\title{
Interplay between Nutrition and Hearing Loss: State of Art
}

\author{
Ana M. Puga ${ }^{1}$, María A. Pajares ${ }^{2,3}$, , Gregorio Varela-Moreiras ${ }^{1,+}$ and Teresa Partearroyo ${ }^{1, *,+(\mathbb{D})}$ \\ 1 Department of Pharmaceutical and Health Sciences, Faculty of Pharmacy, CEU San Pablo University, \\ 28668 Madrid, Spain; anamaria.pugagimenezazca@ceu.es (A.M.P.); gvarela@ceu.es (G.V.-M.) \\ 2 Department of Structural and Chemical Biology, Centro de Investigaciones Biológicas (CSIC), 28040 Madrid, \\ Spain; mapajares@cib.csic.es \\ 3 Molecular Hepatology Group, Hospital La Paz Institute for Health Research (IdiPAZ), 28046 Madrid, Spain \\ * Correspondence: t.partearroyo@ceu.es; Tel.: +34-91-372-47-19 \\ + These two authors contributed equally to this paper.
}

Received: 30 November 2018; Accepted: 21 December 2018; Published: 24 December 2018

\begin{abstract}
Hearing loss has been recently ranked as the fifth leading cause of years lived with disability, ahead of many other chronic diseases such as diabetes, dementia, or chronic obstructive pulmonary disease. Moreover, according to the World Health Organization, moderate-to-profound hearing loss affects about 466 million people worldwide. Its incidence varies in each population segment, affecting approximately $10 \%$ of children and increasing to $30 \%$ of the population over 65 years. However, hearing loss receives still very limited research funding and public awareness. This sensory impairment is caused by genetic and environmental factors, and among the latter, the nutritional status has acquired relevance due its association to hearing loss detected in recent epidemiological studies. Several experimental models have proved that the onset and progression of hearing loss are closely linked to the availability of nutrients and their metabolism. Here, we have reviewed studies focused on nutrient effects on auditory function. These studies support the potential of nutritional therapy for the protection against hearing loss progression, which is especially relevant to the aging process and related quality of life.
\end{abstract}

Keywords: auditory function; presbycusis; noise induced hearing loss; caloric restriction; proteins; lipids; carbohydrates; vitamins; minerals; antioxidants

\section{Introduction}

Hearing loss (HL) is a common disorder that has multifactorial origin, including both genetic and environmental factors [1,2]. Genetic factors include mutations in genes or regulatory elements involved in the development, structure, or function of the cochlea. Among environmental factors, exposure to noise, the increasing use of listening devices, ototoxic drugs (i.e., antibiotics, anticancer drugs, pain killers), or nutritional deficiencies can be listed. Therefore, this is one of the fields in which nutritional intervention studies may have a greater preventive potential, especially when HL is also associated with age [3]. According to the World Health Organization (WHO) around 466 million people worldwide (over 5\% of the world's population) suffer from disabling HL [4]. Its incidence varies in each population segment, ranging from approximately $10 \%$ of children to $35 \%$ of the population over 65 years [2,5]. Moreover, it is estimated that only in Europe, the number of HL cases will increase more than $18 \%$ in the 2010-2020 decade [6]. In fact, estimations indicate that over 900 million people worldwide will have disabling HL by 2050 [4]. Worsening of the situation is highlighted by the fact that HL has moved seven positions towards the top of the ranking of causes of years lived with disability 
since 2010, reaching now the fourth position and placing itself ahead of headline-grabbing conditions such as diabetes or dementia $[7,8]$.

HL has important consequences in the quality of people's lives [9]. The reported effects include: (i) emotional reactions such as loneliness, isolation, depression, anxiety, or frustration; (ii) behavioral reactions namely blaming, withdrawing, or bluffing; and (iii) cognitive reactions including confusion, distracting thoughts, decreased self-esteem, and communication disorders $[8,10,11]$. The final consequence of these effects is a significant increase in the risk of dependence and associated costs. In a recently published report, the WHO estimates the annual cost of unaddressed HL to be globally about 750 billion US dollars [12].

More than twenty-two active randomized clinical drug trials are being conducted currently in the United States of America (USA), some of them with N-acetilcysteine, vestipitant, zonisamide, anakinra, sodium thiosulfate, alpha-lipoic acid, or D-methionine and six potential therapeutic molecules are under research [13]. Interestingly, it is well known that the prevalence and impact of HL can be mitigated through public health actions. As an example, recent estimations suggest that virtually $60 \%$ of HL among children can be prevented through public health measures [3] and around 50\% with immunizations for rubella, mumps, measles, and meningitis [7]. Despite the importance of early diagnosis and appropriate intervention in HL, only a few countries, mainly in the high-income group, have implemented strategic plans to address this injury [14]. Different epidemiological studies worldwide have demonstrated the association between the deficiency of several essential nutrients and HL [15-18], while others also provided evidences of its prevention by means of dietary supplementation [19-21]. Moreover, dietary exposure to potential ototoxic heavy metals such as cadmium and lead [22], obesity (measured as high body mass index and high waist circumference), and reduced physical activity are also related to HL, confirming the negative consequences of an unhealthy diet and lifestyle in the auditory function [9]. Therefore, the aim of this review is to summarize the current knowledge on the effects of dietary habits into the auditory function, the impact of micronutrient deficiencies or insufficiencies and the potential of nutritional therapies in the prevention of HL progression. For a better understanding and follow-up, we have structured this review based on the effects of caloric restriction, macronutrients, micronutrients and other nutrients on auditory function and HL.

\section{Anatomy of the Ear and Hearing Loss}

For a better comprehension of the present review, a slight description of the ear anatomy is included below. The ear is divided into three anatomical compartments: outer, middle and inner ear (Figure 1A). The inner part of the ear contains the cochlea (Figure 1B), responsible for the mechanotransduction of the sound stimulus. The cochlear duct (Figure 1B) has a section with triangular prism shape (scala media) composed by: (i) an external wall, the spiral ligament and stria vascularis; (ii) an upper wall, the Reissner membrane; and (iii) a lower part, the basilar membrane on which the organ of Corti is supported (Figure 1C) [23]. The organ of Corti is a specialized epithelium, which acts as hearing receptor and contains two types of hair cells, outer and inner, innervated by the spiral ganglion neurons that connect it with the brain $[23,24]$. 
A
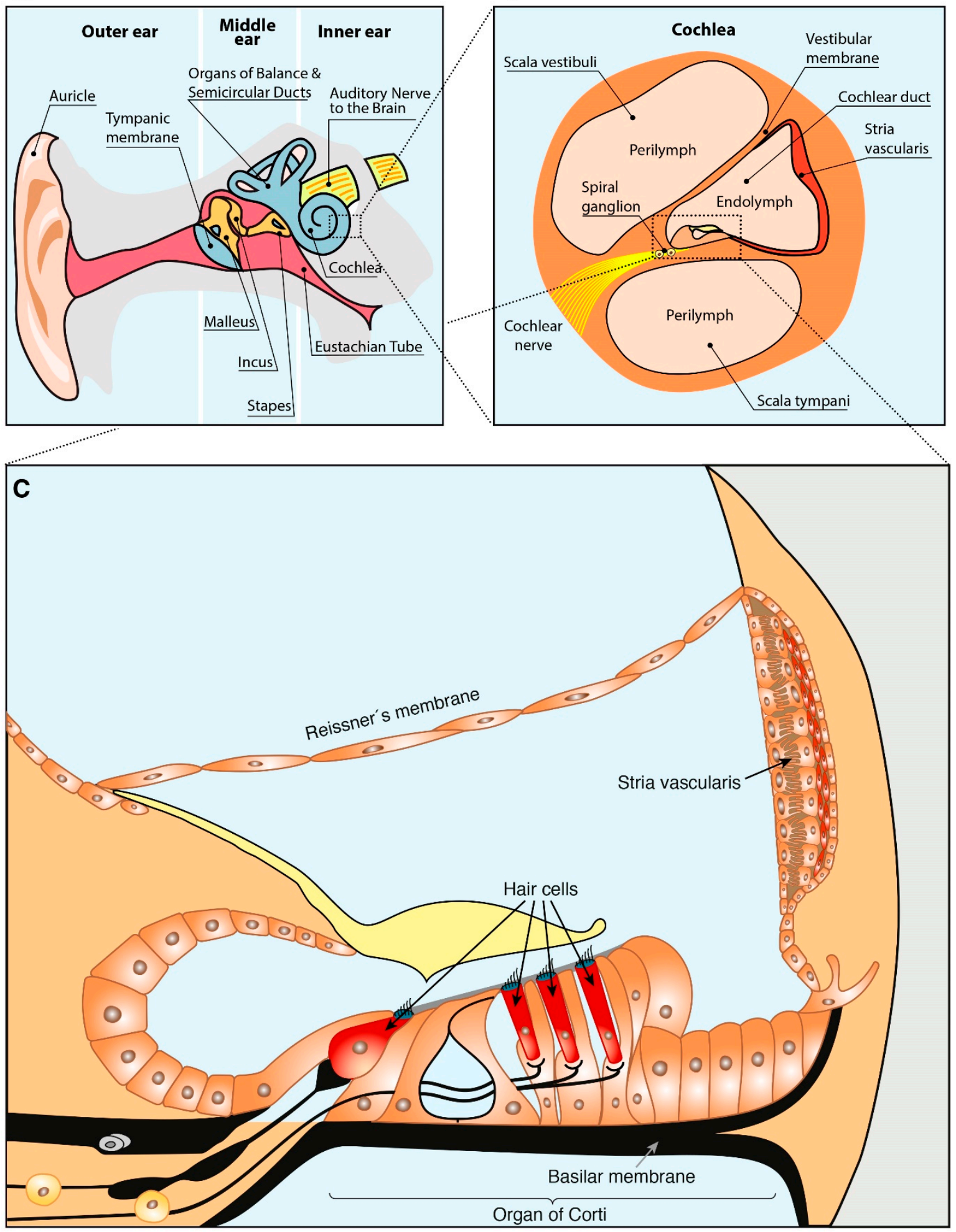

Figure 1. Schematic drawing of the ear anatomy. (A) Ear anatomical compartments. (B) Cochlea anatomy. (C) Structure of the cochlear scala media. Based on Sanchez-Calderon et al. [25] and Rivera T. et al. [26].

There are different criteria to classify HL. According to the location of the injury, HL is classified as: (i) conductive, when the damage occurs either in the middle or the external ear; (ii) sensorineural HL (SNHL), if the injury affects the inner ear (usually the cochlea) or the auditory nervous system; and 
(iii) mixed, a combination of both [11]. Regarding its severity, the American Speech-Language-Hearing Association establishes different degrees of HL depending on the range of decibels of hearing level (dB HL) that are lost: (i) normal ( $-10-15 \mathrm{~dB}$ HL); (ii) slight (16-25 dB HL); (iii) mild (26-40 dB HL); (iv) moderate (41-55 dB HL); (v) moderately severe (56-70 dB HL); (vi) severe (71-90 dB HL); and (vii) profound (above $91 \mathrm{~dB}$ HL) [27]. Considering the age at which the damage appears, HL is classified as: (i) prelocutive or prelingual, appearing prior to the acquisition of language; and (ii) postlocutive or postlingual, arising later on [28]. Finally, HL can be non-syndromic if it is the only dysfunction present or syndromic when associated with alterations in other organs.

Pure tone audiometry is one of the most commonly used methods for assessment of the auditory function. It measures specific frequency thresholds and informs on the conductive or sensorineural origin of the detected HL. However, in recent years different and more objective methods to evaluate the hearing function have been developed, which avoid the high dependence of audiometry on patient's cooperation [29]. Among them, assessment of the auditory brain response (ABR), a non-invasive technique based on the sound-evoked potentials, allows the determination of an objective auditory threshold. Moreover, ABR provides information about the neural transmission conduction through the peripheral and brainstem portions of the auditory pathway [30]. This method is generally used to assess hearing in animal models, although it requires anesthesia.

Different epidemiological studies allowed the identification of HL risk factors and their classification as modifiable and non-modifiable risk factors. Generally, risk factors are classified in 4 different categories: (i) aging; (ii) environmental (occupational and leisure noise exposure [31], treatment with ototoxic drugs [32], nutritional deficiencies [18], smoking and adiposity [11], and even the socioeconomic status); (iii) genetic predisposing (sex, race, or specific genes); and (iv) health co-morbidities (diabetes, hypertension, stroke, and/or smoking) [11,33,34]. More than 300 genes have been associated with hearing [35] and out of them single nucleotide polymorphisms in more than 50 genes have been related to HL [36]. Consistent associations have been established with some non-modifiable risk factors, such as increased age or male ethnic background. For example, Agrawal et al. observed that White and Mexican American men had higher prevalence of bilateral and high-frequency HL, whereas African-American men showed the lowest prevalence among the ethnic groups studied [37]. In any case, lifestyle is a key factor that may influence not only the auditory performance at any age, but also the progression of HL in the elderly, also known as presbycusis or age-related HL (ARHL) [38]. Examples of the influence of life style are diverse. Among them, the increased risk of HL detected in smokers and passive smokers that is dose-dependent [39], the better hearing detected in the elderly with moderate alcohol consumption versus heavy alcohol drinkers, which had a leaning toward more pronounced HL, or the observation that a high body mass index is related to an increased risk to develop HL at high frequencies [40].

The functional decline of the organism during aging is usually associated with a progressive sensory injury that is often concomitant with cognitive decline [41,42], but also with the development of a great variety of chronic illnesses such as cancer, diabetes, atherosclerosis, osteoporosis, and cardiovascular diseases. HL shares common biochemical alterations with some of these chronic diseases that lead to cellular degeneration and organ malfunction [42]. Among these alterations, increased inflammation, impairment of insulin signaling, abnormal proteostasis, oxidative stress and alterations in the intermediary metabolism of the inner ear have been reported [43]. As a consequence, the percentage of elderly people affected by presbycusis increases with age from $30 \%$ in people aged more than 65 to about $80 \%$ in those older than 85 years [44].

Presbycusis is a degenerative disorder identified as SNHL, since the dysfunction arises in the cochlea, specifically in the organ of Corti. Sound-induced vibrations are transduced by sensory hair cells of the cochlea into electrical signals, information that cochlear neurons communicate to the brain $[23,45]$. Both stria vascularis and hair cells are particularly susceptible to damage; hence, their affectation leads to a decline in hearing function. HL in presbycusis usually begins in the high-frequency regions, compromising the understanding of conversations in noisy environments 
and tends to spread toward the low-frequency region during aging [46]. If it reaches the range of 2-4 kHz, important for distinguishing deaf or voiceless consonants (those produced without sound from the vocal cords, such as $\mathrm{f}, \mathrm{k}, \mathrm{p}$, s, or $\mathrm{t}$ ), the understanding of conversations in any situation is affected. HL progresses by approximately $1 \mathrm{~dB}$ per year, once 60 years of age are reached [47]. Among the injuries causing ARHL, age-related loss of hair cells within the stria, oxidative stress (from noise exposure or other causes of free radical production) or microvascular disease of strial vessels should be mentioned [34]. Thus, targeting these traits may offer interesting opportunities to slow down the progression of HL (e.g., using antioxidants) [48,49]. The search for a suitable treatment of these disorders, not only in the elderly but at all stages of life, represents a key health challenge and a major socioeconomic problem [9], especially since the population above 60 is expected to double by 2050 in the European Union [50].

\section{Caloric Restriction and Hearing Loss}

It is well known that one of the most successful strategies to retard the negative impact of aging in the organism is to reduce dietary intake through caloric (CR) and/or dietary restriction (DR); the latter is defined as a reduction in the calorie intake with adequate nutrient levels [51]. In different animal models (rodents and non-human primates), CR has been shown to decrease the incidence of obesity, diabetes and tumors [51-53]. Moreover, CR can protect neurons in animal models of neurodegenerative diseases [54] and decreases the levels of oxidative protein damage in aged brains, hearts and livers [55]. In humans, research of the anti-aging effects of CR is still at an early stage, although it has been demonstrated that CR reduces the incidence of obesity, as well as cholesterol levels, blood pressure, oxidative stress, inflammation, and insulin resistance $[53,55]$. The precise mechanisms by which CR/DR maintain a good health and prolong life is not completely understood, but apparently involve numerous adaptations of cellular metabolism and energy production [56]. One of the most accepted theories is the Mitochondrial Free Radical Theory of Aging, which postulates that aging and age-related diseases result from the accumulation of oxidative damage caused by reactive oxygen species (ROS) originated in the mitochondria. In this context, the major antioxidant defense is carried out by the glutathione and thioredoxin systems. Antiaging effects of CR seem to be associated with the mitochondrial antioxidant defense pathway, but the exact mechanism remains unclear [55]. Although these considerations apply to the general health state, several researchers have tried to elucidate if CR/DR is able to counteract the effects of aging in HL using animal models (Table 1). For example, Mannström at al. performed a detailed evaluation of the impact of DR on the total number of sensory hair cells and spiral ganglion neurons and on the volume and the fine structure of the stria vascularis in Sprague-Dawley albino rats [57]. Interestingly, these rats present high similarities to humans in terms of life span and sensory and motor functions during aging. Comparison of results obtained in animals under DR versus rats fed ad libitum demonstrated that DR maintained the auditory reflex, as well as the cellular integrity of the stria vascularis.

To understand the biochemical mechanisms of the antiaging effect of $C R$, the role of sirtuins, a group of $\mathrm{NAD}^{+}$-dependent protein deacetylases, has been widely studied. Specifically, mitochondrial sirtuin-3 (SIRT3) has the capacity to regulate ATP levels and the activity of complex I of the electron transport chain, thus playing an important role in the metabolic reprogramming mediated by CR [46]. Several studies demonstrated the effect of CR on SIRT3 levels in different settings. As an example, fasting increases SIRT3 protein expression in liver mitochondria [58] or primary mouse cardiomyocytes [59] providing protection against oxidative-induced cell death. Regarding the effect of SIRT3, Someya et al. proved that CR prevents ARHL in C57BL/6J mice, reducing degeneration and inducing Sirt3 in the cochlea, using regular and CR (75\% reduction in caloric intake) diets to feed wild-type and Sirt3-deficient mice [60]. CR delayed the progression of HL in wild-type mice, but not in Sirt3-deficient animals, demonstrating the critical role of this sirtuin in the effect of CR in ARHL. Then, the metabolic effects of CR were studied in both models. The findings indicate lower levels of serum insulin and triglycerides in wild-type, but not in Sirt3-deficient mice, leading the authors 
to conclude that these results are a consequence of the SIRT3 role in metabolic adaptations to CR. Subsequent studies demonstrated that SIRT3 enhances the glutathione antioxidant defense system and decreases ROS levels in mammals under CR conditions, resulting in protection of the inner ear and preventing ARHL [46]. Given the mitochondrial location of this protein, it was postulated that SIRT3 could regulate any of the mitochondrial antioxidant systems. Hence, Someya et al. observed that SIRT3 is able to modulate the reduction of oxidized glutathione after CR. Under these conditions, SIRT3 binds and deacetylates mitochondrial isocitrate dehydrogenase 2 (IDH2), increasing its enzymatic activity. Hence, it was proposed that CR promotes Sirt3 expression, leading to deacetylation and activation of IDH2 and, in turn increasing the resistance to oxidative stress and preventing ARHL [46]. Interestingly, these authors postulate that this is the main mechanism of aging retardation by CR and that pharmaceutical interventions that induce SIRT3 activity will mimic this diet by increasing resistance against oxidative stress and preventing the mitochondrial decline associated with aging. Although anti-aging effects of CR were thought to require a significant reduction of body weight, the study carried out by Someya et al. [46], revealed that despite the significant reduction of body weight in Sirt3 knockout mice, CR failed to slow down the development of ARHL. Therefore, an essential role of specific proteins such as SIRT3 was established, together with the conclusion that weight loss alone is not enough for the preservation of normal hearing.

Studies to evaluate the effect of CR in auditory function have been also performed in additional animal models. Rhesus monkeys (Macaca mulatta) are long-lived primates, phylogenetically closer to humans than rodents, and hence constitute a better model to study the effects of CR in human ARHL. Their maximum lifespan is 40 years and they display a decrease in the auditory function by 25-31 years of age [61]. Moreover, their auditory structures (middle ear, cochlea) and neural function are very similar to those of humans. The University of Wisconsin (UW) study was the first to assess the effect of CR in hearing with a large cohort of animals, using a problem group that was maintained with $30 \%$ less calories than the control group for 3 to 9 years, when the animals aged to between 11 and 23-years old. Results of the auditory tests showed a tendency of ABR thresholds of male monkeys under CR to be lower (better auditory function) than those in the control group (no significant differences) $[62,63]$. Torre et al. evaluated the effect of CR in ARHL comparing monkeys fed a low fat, high fiber diet ad libitum with others fed a 30\% lower amount of the same diet [64]. Studies of the auditory function performed after 12-13 years on these diets (mean ages 18.7-20.4 years), revealed no differences between groups. Finally, other study compared animals fed a control diet versus a diet with $70 \%$ less calories, but supplemented with vitamins and minerals, after a follow up of 8-13.5 years. Auditory tests were performed at a mean age of 20.5 and 20.6 years for the control and CR groups, respectively, and no effects in auditory function were found despite the large energy reduction due to this CR diet [65]. The authors concluded that the duration of CR is a critical factor to observe its protective effects on ARHL, especially considering the long lifespan of Rhesus macaque. Moreover, it is important to consider the age of the animals at the time of the auditory tests. A close analysis of these three studies indicates that monkeys were still relatively young and had not reached the age at which ARHL is normally shown in the auditory tests. Therefore, it would be interesting to evaluate the auditory function of the animals at more advanced ages, to confirm whether CR has any protective effect in the auditory function.

Table 1. Summary of the effects of caloric restriction in the auditory function.

\begin{tabular}{ccc}
\hline Animal Model & Effect & Author and Year \\
\hline Sprague-Dawley albino rats & $\begin{array}{c}\text { Maintenance of the auditory reflex and } \\
\text { cellular integrity of the stria vascularis }\end{array}$ & Mannström et al., 2013 [57] \\
\hline C57BL/6J mice & $\begin{array}{c}\text { Cochlear degeneration reduction and Sirt3 } \\
\text { induction in the cochlea }\end{array}$ & Someya et al., 2007 [60] \\
\hline Rhesus monkeys & Lower ABR threshold compared than control & $\begin{array}{c}\text { Fowler et al., 2002; Ramsey et al., } \\
\text { 2000 [62,63] }\end{array}$ \\
\hline Rhesus monkeys & No differences with control & Torre et al., 2004 [64] \\
\hline
\end{tabular}




\section{Macronutrients and Hearing Loss}

Among macronutrients, the limited research carried out to analyze the impact of carbohydrates and proteins on auditory function and the prevention of HL suggests that they possibly have marginal effects on hearing (Table 2). In fact, the relationship between carbohydrate consumption and HL is thought to be related, not to carbohydrates themselves, but to the triglyceride (TG) serum levels. In this line, diets rich in carbohydrates, especially sugars and concentrated sweets that are highly concentrated in fructose, led to high TG serum levels, and hence, expected to affect auditory function [66,67]. In fact, Gopinath et al. observed that, human adults with high glycemic index, higher glycemic load and overall higher total carbohydrate levels showed an increased risk of HL [68]. In view of the results and in agreement with the opinion of the authors, high postprandial glycemia might be a potential underlying mechanism for developing ARHL.

Regarding the role of proteins in HL, so far, the available studies have been mainly focused on the role of specific proteins such as $\beta$-Conglycinin, one of the major storage proteins of soy. Initial studies performed to analyze the protective effect of this protein against ARHL demonstrated that foods containing $\beta$-Conglycinin are useful for the prevention of obesity and dislipemia [69]. Tanigawa et al. then used six-month-old male C57BL/6J mice that were fed either $\beta$-Conglycinin (study group) or casein (control group) for 6 months [70]. At different time points, ABR tests, analysis of the cochlear blood flow and histological studies were performed. High $\beta$-Conglycinin ingestion prevented the increase of ABR thresholds shown in the control group, preserving the cochlear blood flow and improving the oxidative status [70]. To the best of our knowledge, no epidemiological studies have been carried out to evaluate the effect of this protein in $\mathrm{HL}$, and hence to assess whether the potential beneficial effects observed in animals also apply to humans.

Conversely, numerous and detailed research on the effect of lipid consumption in the auditory function has been carried out (Table 2). The interest on the study of lipid effects on the auditory function is based on the observation that, in the Mabaan tribe, there were no cases of cardiovascular disease or AHRL and that additional studies supported a correlation between cardiovascular events and HL [71,72]. In this context, the connection between $n-3$ polyunsaturated fatty acids (also called $\omega-3$ fatty acids ( $\omega-3)$ ) and HL was suggested by the role of these lipids in the prevention/protection against vascular diseases. Briefly, $\omega-3$ belong to the 18 to 24 carbon family with three or more double bonds, the last of these bonds being located three carbons away from the terminal methyl group (starting at the carboxyl group). Mammals do not have the enzymatic ability to create double bonds beyond the ninth carbon, and so $\omega-3$ must be obtained from the diet. The simplest $\omega-3$ is $\alpha$-linolenic acid (ALA), which is found in certain vegetable oils (flaxseed, canola and soybean) and walnuts. ALA is the metabolic precursor of eicosapentaenoic acid (EPA) and docosahexaenoic acid (DHA), but given the limited capacity of mammals for their synthesis, both must be also provided by the diet, mainly from fish and fish oil. Their beneficial vascular effects are related to a variety of actions, including their hypolipidemic, anti-inflammatory and anti-atherotrombotic properties and their capacity to lower TG levels. EPA, DHA, and ALA are candidate molecules for cardiovascular disease prevention [73], although differences among them have been shown. For example, EPA is known to be more effective than DHA in reducing inflammation [74], therefore it could be expected to be more effective in the prevention of HL. The relationship between between cardiovascular disease, risk factors and auditory status was studied by Gates et al. in the Framingham cohort [75], observing a moderate association between cardiovascular events (including ischemic heart disease, myocardial infarction and stroke) and HL. In parallel, different animal models have given insights into the relationship between AHRL and vascular events. As an example, gerbils present progressive reduction of the blood flow and microvascular alterations in the stria vascularis and spiral ligament, which are related to HL and aging [76]. These data suggested that, because of the decreased blood flow, the cochlear supply of essential nutrients (including $\omega-3$ ) is reduced, leading to metabolic alterations and triggering the progression of HL. 
A preliminary epidemiological study was carried out in Finland in the 1970s in two different psychiatric hospitals to evaluate the effect of different dietary lipids in the auditory function. During a 5-year period, one hospital maintained the usual high saturated fat diet, whereas it was substituted by high polyunsaturated fat in the other. At the end of this period, the incidence of coronary problems and the number of people showing auditory impairment were significantly lower in the second hospital. Then, diets of both hospitals were interchanged and four years later, the inverse results were observed. Thus, it was established that auditory function improves with a diet rich in polyunsaturated lipids, whereas it deteriorates with high-saturated fat; the incidence of coronary diseases followed the same pattern. The Finnish investigators concluded that the diet is a critical factor to prevent coronary heart diseases and that it may well stop or even reverse HL [19]. Some years later, a cross-sectional and 3-year longitudinal study was carried out by Dullemeijer et al. to investigate if plasmatic levels of long chain $\omega-3$ were associated with ARHL [20]. Volunteers were classified into quartiles according to their plasmatic proportions of long chain $\omega-3$. Results showed a better auditory function at low frequencies in volunteers belonging to the highest quartile of plasma long chain $\omega-3$ as compared to those in the lowest quartile over the three years of study. However, plasmatic levels of $\omega-3$ showed no association with $\mathrm{HL}$ in the high frequencies. These differences were ascribed to the fact that the apex of the cochlea transduces the low-frequency sounds, whereas the base transduces high frequency ones. Moreover, blood supply lies farther away from the apex than from the base. Thus, in the event of vascular disease, the apex may be more prone to changes in microcirculation, resulting in alterations of the auditory function at low frequencies. Conversely, improvements in microcirculation caused by high plasma long chain $\omega-3$ levels may be associated to decreases of low-frequency thresholds [20]. Despite its interest, limitations of this study include that half of the volunteers received folic acid (FA) supplementation for three years, due to their participation in a randomized controlled trial. Since FA is known to slow down the decline of HL in low frequencies [77], a certain bias in the results might be expected.

Some other studies have focused on the effect of fish consumption, rich in $\omega-3$, in the auditory function. A prospective Australian study carried out in women evaluated the association between dietary intake of $\omega-3$ from fish and the risk of presbycusis, finding that high dietary intake of these lipids was associated with a $24 \%$ decrease in the risk of developing HL. Researchers observed as well that regular ingestion of fish ( $>1$ but $<2$ servings / week) was negatively associated with the 5-years incidence and progression of HL in older adults, but higher fish consumption ( $>2$ servings/week) did not protect against its progression. These findings suggested the existence of a threshold of the beneficial effect at 1-2 servings of fish/week. However, when fatty acids were analyzed individually, it was not possible to establish an association between dietary intake of ALA and the incidence of HL, possibly due to its poor conversion $(<5 \%)$ to EPA and DHA [73]. Finally, as observed in previously mentioned studies, significant inverse association between dietary total long chain $\omega-3$ in plasma and HL prevalence was found [21]. In general, these results confirmed the potential of changes in the nutritional status of older adults as a possible strategy to diminish the public burden of ARLH [21]. The effect of $\omega-3$ consumption was studied not only for presbycusis, but also for HL in general population. Curhan et al. prospectively examined the relationship of total fish intake, consumption of specific fish types, ingestion of long-chain $\omega-3$ and the risk of self-reported HL in a cohort of 65,215 American women aged 27-44, who were followed for 18 years [78]. Results of this study showed that women who consumed 2 or more fish servings per week, independently of the fish type (tuna, dark-meat fish, light-meat fish, or shellfish) presented a reduction in HL and, additionally, the higher intake of long-chain $\omega-3$ were inversely associated with risk. Although these results were consistent with those of the Australian study previously explained, differed from data of another cross-sectional European study in which no association between fish intake and hearing levels was found in women [79]. The authors concluded that these differences rely in the small population analyzed and the cross-sectional design of the European study that prevented the establishment of temporal relationships. 
In contrast, animal studies rendered different results. Church et al. used Wistar rats to evaluate the putative effects that $\omega-3$ ingestion during pregnancy and lactation have in the offspring lifespan, brain and sensory development and function (evaluated using ABR) [80]. In this study, the animals were fed three different diets from the first day of pregnancy until end of lactation: control, $\omega-3$ deficient and high $\omega-3$ diets providing $\omega-3 / \omega-6$ ratios ranging from 0.14 to 14 . Permanent raises in ABR thresholds, i.e., $\mathrm{HL}$, in the offspring from rats fed an excess of $\omega-3$ were detected, together with abnormally large ABR amplitudes in response to high stimulus intensities (i.e., hyperacusis), due to compromised neural inhibition. It was hypothesized that these adverse effects could be caused by several mechanisms, among which two can be highlighted: (i) alterations in cell membrane, organ, brain and sensory function due to excessive $\omega-3$ plus low arachidonic acid levels in blood; and (ii) the oxidative stress and subsequent cell apoptosis induced by the high ingestion of $\omega-3$. Thus, the authors emphasized that $\omega-3$ excess or a high $\omega-3 / \omega-6$ ratio during pregnancy and lactation, as well as in infant formula feeding could result in sensory disorders [80].

In addition to the role of $\omega-3$ in cardiovascular disease and HL, these lipids show also beneficial effects in inflammation and oxidative stress. Furthermore, high plasmatic levels of homocysteine (Hcy) are an independent risk factor for cardiovascular and HL and several epidemiologic studies have shown opposite effects of fish oil supplementation [81,82]. These data prompted Martínez-Vega et al. to perform a study focused on the putative benefit of an $\omega-3$ supplemented diet on cochlear Hcy metabolism using a classical model of early HL, the C57BL/6J mice. Two experimental groups, which were fed control or $\omega$-3-supplemeted diets ad libitum for 8 months, were analyzed. The results obtained showed that the $\omega$-3-supplemeted diet improved HL and led to changes in the cochlear Hcy metabolism and to modifications in cytokine levels. Likewise, this study revealed that high $\omega$-3-supplemeted diet prevented changes in the expression of proinflammatory cytokines, and Bhmt and Cbs genes (both involved in Hcy metabolism). Furthermore, there was an increase in BHMT, an enzyme involved in remethylation of Hcy for the conservation of methionine levels [83]. This cluster of results confirmed the close relationship between Hcy and $\omega-3$ metabolism and consequently with HL. In the vitamins section of this review the role of FA, whose deficit leads to elevations in plasmatic Hcy levels, in HL will be deeply analyzed.

Many other researchers focused not on the potential beneficial effects of $\omega-3$, but on the detrimental association between dietary intake of fats (saturated and cholesterol) and HL. Studies using different animal models (guinea pigs and chinchillas) showed an increase of hearing thresholds when feeding high-fat diets [84,85]. This association was also examined in humans by Gopinath et al. [86], which carried out a cross-sectional and longitudinal study to evaluate the relationship between dietary fats, certain food groups and SNHL, as well as to assess the association between serum lipids, the use of statins (cholesterol lowering drugs) and the progression of ARHL. This study found that high dietary intake of cholesterol was associated with an increased risk of developing SNHL. Among the mechanisms that could explain this association, disturbances of cochlear vasculature and atherosclerotic inflammatory changes, causing reduction of oxygen and nutrient supply together with decreased elimination of waste material, were mentioned. Neither dietary fat intake nor serum lipids showed any association with the incidence of HL. Hence, it was suggested that attention should be paid to the dietary patterns, specifically cholesterol intake, rather than serum lipid levels, as potential modifiable factors for the prevention of ARHL. 
Table 2. Main results of research studies that evaluate the effect of macronutrients on the auditory function.

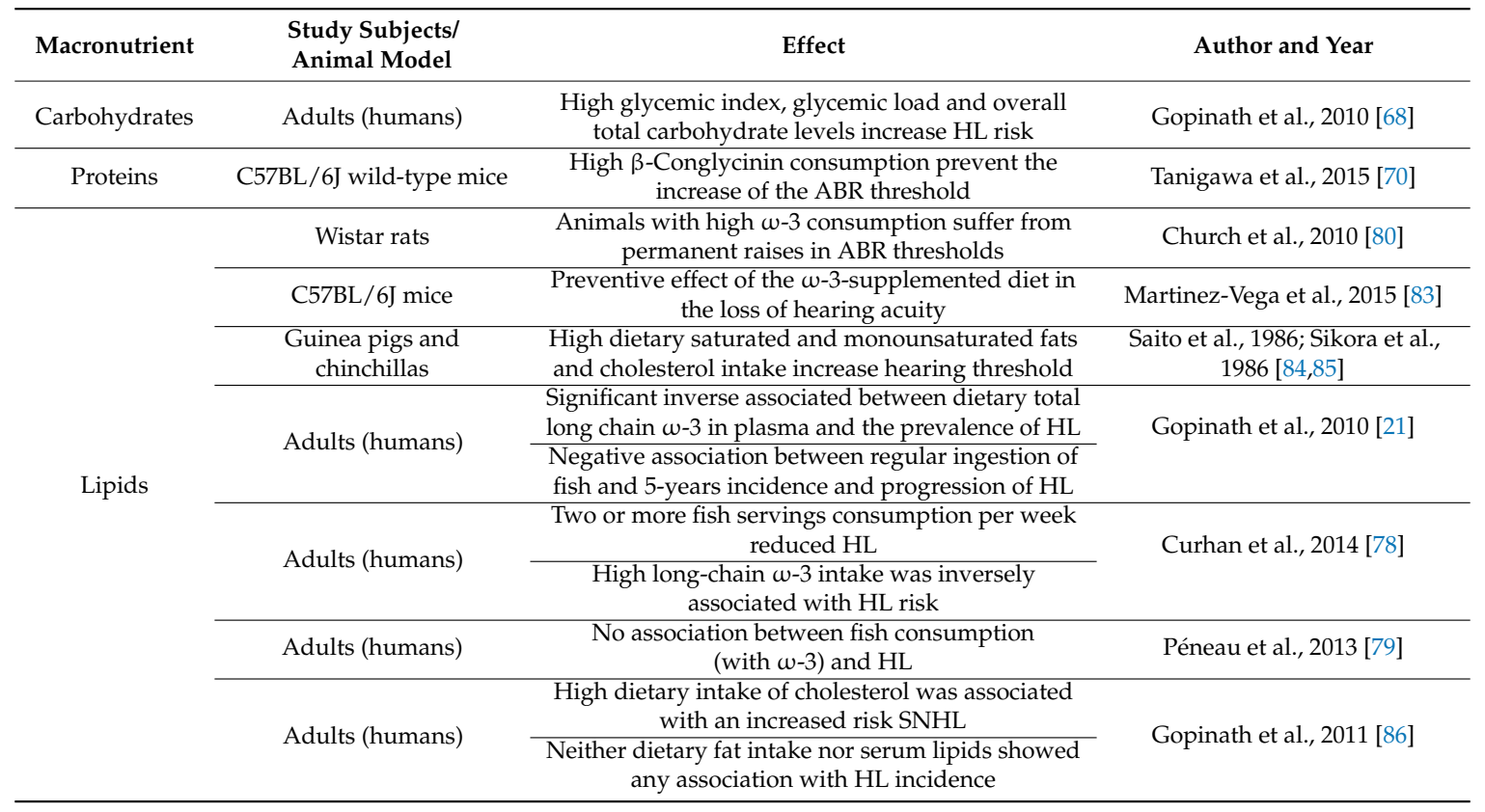

\section{Micronutrients and Hearing Loss}

\subsection{Vitamins and Hearing Loss}

The study of the effect of vitamins in HL has attracted the attention of numerous researchers. Vitamins, as micronutrients, have potential beneficial effects in the treatment/prevention of HL due to either their antioxidant properties or their essential role in the proper functioning of the ear. Several researchers have performed different animal or epidemiological studies to analyze the effect of these micronutrients in the auditory function (Tables 3 and 4). Likewise, other studies have focused on the role of supplementation in the improvement of the auditory function (Table 5). Vitamins with antioxidant properties may prevent cochlear damage caused by high levels of toxic ROS produced e.g., during and after noise exposure. Therefore, most studies have focused on the preventive effect of their administration against noise-induced HL (NIHL), although some also focused on the ability of dietary antioxidants to prevent drug-induced ototoxicity [87]. Among others, chemicals such as glutathione, $\mathrm{N}$-acetyl-L-cysteine, R-phenylisopropyladenosine and 2-oxothiazolidine-4-carboxylate were used to increase antioxidant levels. However, these approaches have important drawbacks regarding the drug administration route and the timing of multiple doses relative to noise exposure, so that the antioxidant is available in the cochlea at the time of ROS generation. Hence, dietary supplementation with antioxidant vitamins, such as vitamin C (ascorbate), E ( $\alpha$-tocopherol) and A (retinol), has been consider an alternative route to overcome these limitations. Therefore, different studies have deepened into their individual or combined effects in auditory function by means of the diet or the administration of supplements. For example, the effect of vitamin $C$ supplementation in the prevention NIHL was evaluated by McFadden et al. in guinea pigs using three diets: normal, vitamin $\mathrm{C}$ deficient and supplemented diets [88]. No differences in ABR parameters were found among groups before noise exposure. However, post-exposure thresholds were approximately $15 \mathrm{~dB}$ lower in the supplemented group compared to the normal and deficient groups. Vitamin $C$ supplementation also decreased significantly the permanent threshold shift in guinea pigs, whereas its deficiency had no effects on HL. These preliminary results offer interesting perspectives for development of practical approaches to prevent unavoidable damage caused by noise exposure, although additional studies using other models and vitamin $C$ doses must be performed. Another study used Wistar albino rats to 
analyze prevention against cisplatin ototoxicity by a dose of vitamin $B_{1}, B_{2}, B_{6}, E$, C or L-carnitine. ABR threshold and distortion product otoacoustic emissions were recorded $72 \mathrm{~h}$ after drug administration showing that vitamins and L-carnitine contributed to decrease or prevent cisplatin-induced ototoxicity, thus opening a very interesting pathway for its potential study and use in humans [87].

Since the antioxidant properties of vitamins A, C and E are exerted by different mechanisms, synergistic effects among dietary antioxidants and other dietary components can take place. As examples of different antioxidant mechanisms, vitamin $\mathrm{E}$ is a donor antioxidant in the cell membrane that reduces peroxyl radicals, inhibiting the propagation cycle of lipid peroxidation and vitamin $\mathrm{C}$ detoxifies free radicals in aqueous phase by means of their reduction $[89,90]$. Among other dietary components that can induce synergistic effects, magnesium should be considered. This mineral, mainly found in dried fruits and nuts and in legumes, reduces the formation of free radicals and thus noise-induced vasoconstriction [48]. Therefore, putative synergisms have been analyzed by Le Prell et al. using four groups of guinea pigs that received: (i) saline injections; (ii) a combination of vitamin A, C and E; (iii) only magnesium; and (iv) vitamins A, C and E plus magnesium. NIHL in animals that received the combined supplement of vitamins and magnesium was significantly reduced (lower ABR thresholds) than in the other groups. Thus, synergistic effects of vitamins $A, C$ and $\mathrm{E}$ with magnesium were confirmed [91]. Furthermore, analysis of synergistic effects was extended using the C57BL/6 mice and six different antioxidants (L-cysteine-glutathione mixed disulphide, ribose- cysteine, NW-nitro-L-arginine methyl ester, vitamin $\mathrm{B}_{12}$, folate and ascorbic acid) that target four different sites within the oxidative pathway. After feeding the combined antioxidant therapy, a decrease in the threshold shift from baseline at all tested frequencies was detected compared to the control group [92]. This combination was also used in a longitudinal epidemiological study that analyzed the association between dietary antioxidants and ARHL in a cohort of Australian adults and evaluated its relation with the prevalence and 5-year incidence of HL [93]. Dietary data were analyzed using a food frequency questionnaire with 145 items that included reference portion sizes. Although this study demonstrated that higher intakes of vitamin A and E resulted in an inverse association with the prevalence of HL, it was not possible to demonstrate a reduction of the HL prevalence due to the intake of antioxidant combinations as shown in animal models. According to the results, dietary antioxidant consumption, alone or in combination, was unable to predict the 5-year incidence of ARHL. Another study evaluated a USA population aged 20-69 years using data from NHANES (National Health and Nutrition Examination Survey) 2001-2004, in which both food and dietary supplements were considered [94]. In contrast to animal studies, a dose-dependent trend between all individual nutrients and lower (better) speech pure tone average at both speech and high frequencies were reported, except for vitamin E. Moreover, this human study also provided evidence of the synergistic effect of high intakes of $\beta$-carotene and vitamin $C$ with magnesium and a lower (better) pure tone average at high frequencies, and hence a reduced risk of HL.

Remarkably, experimental models have demonstrated the importance of the genetic background in the dietary effects on HL progression. Dietary supplementation with $\beta$-carotene, vitamins $C, E$, and magnesium (ACEMg) to two animal models of hereditary deafness, the Gjb2-CKO (childhood deafness) and Diap3-Tg (auditory neuropathy), showed opposite results. The ACEMg diet slowed down the progression of HL in Gjb2-CKO mice and prompted a small but statistically significant improvement of auditory thresholds, probably owing to enhanced hair cell preservation. Conversely, in Diap3-Tg mice the diet had a detrimental effect, increasing HL compared to control fed animals [95]. Thus, these data suggest that only in certain backgrounds of genetic HL it is possible to modulate the phenotype by means of dietary supplementation. Importantly, Diap3-Tg mice present mutations in the Cx26 gene, encoding connexin 26, which is the most common cause of SNHL. Lack of Connexin 26 triggers extracellular accumulation of potassium ions that results in an increase of glutamate concentrations, and hence oxidative stress [96]. These authors previously published a case-report where a boy with Cx26-related HL received ACEMg supplementation daily for three years and that, prior to the start of this regime, had a progressive worsening of the auditory function. As the supplementation began, 
audiometric evaluations confirmed no further progression of HL [97]. Of note, daily doses of each vitamin were higher than the recommended daily intake, but lower than the upper limit $(15,500$ and $364 \mathrm{mg}$ /day for vitamin A, C and E, respectively), whereas for magnesium the daily dose was lower than the recommended daily intake $(167 \mathrm{mg} /$ day). Therefore, it seems that these micronutrients play an essential role as antioxidants in the prevention of HL progression.

On the other hand, a Korean study performed in 2011 with more than 3200 subjects 50 to 80 years old, evaluated the effect of dietary vitamin intake and vitamin $\mathrm{D}$ serum concentrations in auditory function [98]. Carotenoid, retinol, thiamine, riboflavin, niacin and vitamin C intake were assessed by means of a 24-h recall. Evaluation of the auditory function included a physical examination of the ear to discard external or middle ear disease and a pure-tone audiometry to rule out conductive HL. High dietary intake of vitamin $C$ was positively associated with a better auditory function in the midfrequency range. Hearing in the high and low frequencies was also improved in participants of the highest quartile of this vitamin. Regarding retinol, niacin and riboflavin consumption, only univariate linear regression analyzes showed significant correlation with better hearing at selective frequencies, indicating a minor association of these vitamins with HL as compared to factors such as age or noise exposure. Since vitamin consumption tends to decrease with age, the putative protection they offer will be reduced as life extends [99]. This study also presented association of high vitamin D serum concentrations and worse auditory function, a result that was in agreement with previous works that showed that vitamin D-deficient diets prevent ARHL in a mouse model [100] and that chronic sun exposure in the elderly could be a risk factor for HL [101].

The effect of the diet, by means of both nutrients and food group patterns, in the auditory threshold of a sample of French adults was also analyzed, as a continuation of a study that evaluated effects of dietary supplementation with antioxidant vitamins and minerals at nutritional doses on the incidence of cancer and ischemic cardiovascular disease [102]. At the end of the supplementation, some participants were included in an observational study to investigate the impact of nutrition in the quality of aging, including hearing function. Higher intakes of retinol and vitamin $\mathrm{B}_{12}$ were found to be associated with better auditory function only in women. Conversely, no association was found for $\beta$-carotene, folate and vitamins $B_{6}, C$ and $E$. Regarding food intake, women with higher consumption of meat as a whole, as well as red and organ meat, had better hearing levels compared to those with lower consumption of these food groups. For men, a higher consumption of seafood and shellfish improved auditory function [79]. This interesting study however has several limitations that must be taken into account, including the lack of consideration of confounders such as ototoxic medication, habitual noise exposure at work, medical conditions or genetic factors. In this line, a long-term study performed in the USA between 1991-2001, examined the association between intake of carotenoids, vitamins A, $\mathrm{C}$ and $\mathrm{E}$ and folate and the risk of HL in 65,521 women nurses [103]. Vitamin intake was assessed five times, with a gap of five years between each evaluation, using a food-frequency questionnaire. Interestingly, this study included covariates not analyzed in that of Péneau et al. such as hypertension or diabetes history and the consumption of potentially ototoxic medication such as acetaminophen or ibuprofen [79]. Inverse correlations between carotenoids ( $\beta$-carotene and $\beta$-cryptoxanthin) and folate intakes with risk of acquired HL were observed. However, higher vitamin $C$ intake from supplements and higher risk of HL were found, whereas no significant associations for vitamin A, E, and other carotenoids were detected [103].

Vitamin A, in the form of its active metabolite retinoic acid, is required for the normal development of the inner ear. In addition, in case of deficiency, malformations occur in a dose dependent-manner [104]. Vitamin A plays an essential role in the prevention of SNHL, especially during gestation, as showed by different studies $[105,106]$. Moreover, the existence of a synergism between vitamin A deficiency and infections is well known, as well as its relationship with increased risk of otitis media, whereas vitamin A supplementation could reduce the risk of HL due to otitis media. Based on this evidence, some authors consider that providing adequate amounts of vitamin A may reduce the risk of SNHL induced by its gestational deficiency [106]. To the best of our knowledge, 
only one study has been performed to date to elucidate if vitamin A supplementation improves auditory function. Preschool children received vitamin A supplementation, or a placebo capsule, every four months and their auditory function was assessed during their adolescence or early adulthood, sixteen years later [105]. In this setting, supplementation reduced the risk of HL associated with childhood ear infections. The authors postulated that this protective effect of vitamin A in HL may be due to an improvement of vitamin A-regulated defense systems, which entail maintenance of the epithelial integrity, modulation of oxidative stress and of the immune response, hence preventing all the inflammatory processes that cause hearing impairment [105]. However, important limitations of this study (i.e., only HL from middle ear infection was studied) indicate that further work is needed to elucidate if the dietary supplementation with this vitamin, either during gestation or in the early childhood, has a preventive role in HL either in animals or humans.

Vitamin $B_{12}$ and FA deficiencies are the most common vitamin inadequacies in the elderly (jointly with vitamin D), and undoubtedly, the most studied in the auditory field. Vitamin $B_{12}$ deficiency increases with age, mainly due to decreased production of acid and digestive enzymes needed to cleave the vitamin form found in food, and to the lack of intrinsic factor owing to the autoimmune destruction of gastric parietal cells caused by pernicious anaemia. According to NHANES data, the prevalence of vitamin $B_{12}$ deficiency was estimated to be 2.9 to $25.7 \%$, increasing with age and being generally higher in women than in men [107]. Vitamin $B_{12}$ and FA play an important role in cellular metabolism (e.g., Hcy metabolism), the nervous system and vascular function, hence being also important in principle for the auditory function. Moreover, high Hcy concentrations, associated with low vitamin $\mathrm{B}_{12}$ or FA status or both, is a recognised risk factor for cerebral, coronary and peripheral vascular disease [108], hence affecting cochlear blood flow. A recently published review deeply analyzes Hcy metabolism and its relationship with cochlear function, its connection with SNHL, as well as its improvement by $\omega-3$ supplementation [109]. In addition to Hcy serum concentrations, serum methylmalonic acid (MMA) is also useful to predict vitamin $B_{12}$ deficits [107]. This parameter was used in a study of auditory function in older volunteers, showing that impaired hearing correlated with significantly higher MMA levels [110]. Additionally, vitamin $\mathrm{B}_{12}$ levels have been also related to other pathologies of the auditory system, such as tinnitus that is defined as the perception of sound in the absence of an external stimulus. In fact, a Turkish study detected that $63 \%$ of the patients with tinnitus had low $B_{12}$ levels, whereas normal levels were found in a $37 \%$, but no statically significant differences were observed as compared to the control group. Moreover, vitamin $\mathrm{B}_{12}$ replacement treatment was ineffective in improving the symptoms of tinnitus [111]. Considering the wide aetiology of tinnitus, further research is needed to find both, the causes and an effective treatment.

The relationship between FA, Hcy and auditory function has been evaluated in different animal models. Kundu et al. [112] analyzed the effect of FA supplementation in drinking water in hyperhomocysteinemic mice $\left(\mathrm{Cbs}^{+-}\right)$by means of a four-week treatment with a dose equivalent to $400 \mu \mathrm{g} / 70 \mathrm{~kg} /$ day and hearing thresholds were determined by ABR. Their findings suggested an improvement of hearing function through this supplementation, delineating, at the same time, a potential mechanism responsible for Hcy-associated-HL related to the levels of NOX subunits p22phox and p47phox and oxidative stress. Martínez-Vega el al. analyzed the auditory function in C57BL/6J mice, a mouse strain prone to $\mathrm{HL}$, administering standard or folate-deficient diets for eight weeks. These authors observed that animals fed the FA deficient diet had an early onset of HL showing severe histological damage, impaired cochlear Hcy metabolism and oxidative stress [113]. These results were confirmed in a long-term study on the effects of FA deficiency using the CBA/J mouse strain with delayed HL onset, in which, again, the deficiency caused premature HL [114]. In both models, these results correlated with cochlear histological alterations. Differences observed in the initial signs of HL (2 months in C57BL/6J versus 8 months in CBA/J mice) indicate that the impact of the diet depends strongly on the genetic background. A recent pilot study analyzed the influence of different polymorphisms in genes of folate metabolism in the aetiology of presbycusis. Precisely, polymorphisms of 5,10-methylenetetrahydrofolate reductase (MTHFR), methionine synthase (MTR, 
catalysing Hcy remethylation) and thymidylate synthase (TYMS) on the onset of HL were evaluated. Remarkably, this study identified the association of variations in MTHFR and TYMS with ARHL, findings that could be of use for the prompt diagnosis of presbycusis [115].

Since both vitamin $B_{12}$ and FA deficiency increase Hcy serum concentrations, most studies focused in the two vitamins together. Houston et al. were the first to evaluate the relationship between both vitamins and human auditory function in women aged 60-71 years [116]. Blood analyses, dietary records and auditory exams were performed to evaluate the influence of these vitamins and consistent associations were found between ARHL and low serum vitamin $\mathrm{B}_{12}$ and red cell folate. Since vitamin $B_{12}$ and FA serum levels were highly correlated, it was impossible to identify whether any of these vitamins individually had a stronger association with pure-tone averages. Data from dietary analysis showed that auditory function presented a stronger association with folate intake rather than with vitamin $B_{12}$ ingestion, the latter ascribed to $B_{12}$ malabsorption due to the atrophic gastritis commonly found in the elderly. Lasisi et al. found that low serum levels of these two vitamins were significantly associated with HL at high frequencies in elderly volunteers [16]. At the same frequencies after adjusting for age, significant correlations were found with folate but not with $\mathrm{B}_{12}$. A cross-sectional Danish study evaluating 91 adults aged 67-88 years resulted in non-significant associations between serum folate, vitamin $B_{12}$, Hcy and HL [117]. In order to clarify these contradictory results, a large prospective study in a representative old population cohort was carried out by Gopinath et al. for 5 years [118]. This study showed that nearly two-thirds of the people with high serum Hcy levels suffered from HL, whereas only one-third of those with normal serum Hcy levels presented this impairment. Additionally, low serum folate status increased 39\% the risk of developing prevalent HL, whereas serum vitamin $B_{12}$ levels had no association with ARHL. Regarding the 5-year incidence of HL, neither Hcy nor folate nor vitamin $B_{12}$ serum levels showed predictive potential. The authors concluded that further studies with more participants and a longer follow-up are needed to evaluate the influence of Hcy and these vitamins as modifiable risk factors to reduce the AHRL incidence. A large prospective study, including more than 26,000 men with different health professions, aged 40-75 years at baseline in 1986, was performed and the follow up lasted until 2002. Their vitamin intake was assessed with a semi-quantitative food frequency questionnaire, as well as information on self-reported professionally diagnosed HL. This study reported no prospective associations between vitamin $C, E, \beta$-carotene or folate consumption and incident HL. However, higher folate intakes were associated with $21 \%$ reduction in the risk of $\mathrm{HL}$ in men aged from 60 years onward, but only observed in those volunteers with intakes $\geq 800 \mu \mathrm{g} /$ day [119]. This value is considerably higher than the actual minimum recommendations for this vitamin, i.e., $400 \mu \mathrm{g}$ /day for this age group. The main drawback of this study relies in the assessment of HL that was based on self-reported professionally diagnosed HL, probably underreporting other cases of HL. All these data should be considered for further studies, as well as the increased risk of folate malabsorption and depletion in the elderly.

The relationship between low FA status and HL prompted Durga et al. to perform a double-blind, randomized, placebo-controlled trial to elucidate the effect of daily oral FA (800 $\mu \mathrm{g})$ supplementation for 3 years [77]. Their results demonstrated that FA supplementation considerably slowed the decline of auditory function only at the speech frequencies, but not at high frequencies. Regarding the effect of vitamin $B_{12}$ supplementation, a study conducted in the USA involving 93 volunteers aged 58-92 years was unable to demonstrate that this supplementation improved the hearing status in $\mathrm{B}_{12}$-deficient volunteers [110]. Despite the interest of these preliminary results, we can conclude that further studies should be performed considering the potential adverse effects of high doses of these vitamins. For example, results of a recently published study showed that adequate folate intake is beneficial for hearing, but a non-significant association with increased risk of HL was observed in volunteers with the higher folate intakes. The reason for this relationship is unclear, but the authors hypothesized that it could be related to the neurological damage associated to an excess of FA consumption [120]. Moreover, these adverse effects are thought to be worse in individuals with $B_{12}$-deficiency [121]. Hereafter, supplementation with FA should be only administered to population subgroups with high 
risk of folate deficiency, to avoid the side effects of its excessive consumption. Therefore, these data reinforce the involvement of alterations in FA and Hcy metabolism in hearing disorders, although the mechanisms by which the cochlear function is affected remain poorly understood.

Table 3. Main results of studies with animal models that evaluate the effect of micronutrients in the auditory function. HL: hearing loss; FA: folic acid; SNHL: sensorineural HL; ARHL: age-related HL.

\begin{tabular}{|c|c|c|c|}
\hline Micronutrient & Animal Model & Effect & Author and Year \\
\hline Vitamin C & Guinea pigs & $\begin{array}{c}\text { Supplementation significantly decreased } \\
\text { the permanent ABR threshold shift } \\
\text { whereas deficiency had no effects } \\
\text { on NIHL }\end{array}$ & McFadden et al., 2005 [88] \\
\hline Vitamins B1, B2, B6, E, C & Wistar albino rats & $\begin{array}{l}\text { Vitamins contributed to decrease or } \\
\text { prevent cisplatin-induced ototoxicity }\end{array}$ & Tokgöz SA, et al., 2012 [87] \\
\hline $\begin{array}{l}\text { Vitamin } \mathrm{A}, \mathrm{C}, \mathrm{E} \text { and } \\
\text { magnesium }\end{array}$ & Guinea pigs & $\begin{array}{l}\text { Synergistic effects of vitamins } \mathrm{A}, \mathrm{C} \text { and } \mathrm{E} \\
\text { with magnesium in the reduction of } \\
\text { noise-induced threshold }\end{array}$ & Le Prell et al., 2007 [91] \\
\hline Dietary antioxidants & C57BL/ 6 mice & $\begin{array}{l}\text { Synergistic effect of the antioxidants } \\
\text { decreasing the threshold shift from } \\
\text { baseline at all frequencies compared to } \\
\text { control group }\end{array}$ & Heman-Ackah et al., 2010 [92] \\
\hline $\begin{array}{c}\beta \text {-carotene, vitamins } C, \\
E \text {, and magnesium }\end{array}$ & $\begin{array}{c}\text { Mice model of hereditary } \\
\text { deafness (Gjb2-CKO and } \\
\text { Diap3-Tg) }\end{array}$ & $\begin{array}{c}\text { Dietary supplementation slowed down } \\
\text { the progression of HL and improved } \\
\text { auditory thresholds in Gjb2-CKO mice } \\
\text { HL increase in Diap3-Tg mice compared } \\
\text { to control }\end{array}$ & Green et al., 2016 [95] \\
\hline Folic acid & Cbs+/- Mice & $\begin{array}{c}\text { FA supplementation in } \\
\text { hyperhomocysteinemic mice led to } \\
\text { improvement of hearing function }\end{array}$ & Kundu et al., 2012 [112] \\
\hline Folic acid & C57BL/6J mice & $\begin{array}{c}\text { HL detected after two-months on a FA } \\
\text { deficient diet }\end{array}$ & Martinez-Vega el al., 2015 [113] \\
\hline Folic acid & $\mathrm{CBA} / \mathrm{J}$ mice & $\begin{array}{c}\text { Initial signs of HL detected after } \\
\text { 8-months of vitamin deficiency } \\
\text { Correlation between HL, } \\
\text { hyperhomocysteinemia and histological } \\
\text { damage in the cochleae }\end{array}$ & Martinez-Vega el al., 2016 [114]. \\
\hline Nicotinamide riboside & C57BL/ 6 mice & $\begin{array}{c}\text { Nicotinamide riboside administration, } \\
\text { twice daily for } 5 \text { days before noise } \\
\text { exposure and for } 48 \mathrm{~h} \text { thereafter, } \\
\text { prevented NIHL }\end{array}$ & Brown et al., 2014 [122] \\
\hline Iron & Guinea pigs & $\begin{array}{l}\begin{array}{l}\text { Higher ABR thresholds (worse acuity) } \\
\text { were detected in females fed with iron } \\
\text { deficient diet }\end{array} \\
\text { Iron-deficient pups suffered from SNHL }\end{array}$ & Jougleux et al., 2011 [30] \\
\hline
\end{tabular}

Table 4. Main results of the epidemiological studies that evaluate micronutrients effects on hearing loss.

\begin{tabular}{|c|c|c|c|}
\hline Micronutrient & Study Subjects & Effect & Author and Year \\
\hline \multirow{3}{*}{$\begin{array}{l}\text { Carotenoid, retinol, } \\
\text { thiamine, riboflavin, niacin } \\
\text { and vitamin C }\end{array}$} & \multirow{3}{*}{ Adults } & $\begin{array}{l}\text { High dietary intake of vitamin C was associated with a better } \\
\text { auditory function }\end{array}$ & \multirow{3}{*}{ Kang et al., 2014 [98] } \\
\hline & & $\begin{array}{c}\text { Retinol, niacin and riboflavin consumption showed minor } \\
\text { association with HL }\end{array}$ & \\
\hline & & $\begin{array}{l}\text { Vitamin D serum concentration associated with worse } \\
\text { auditory function }\end{array}$ & \\
\hline \multirow{2}{*}{$\begin{array}{l}\text { Retinol, vitamin } B_{12} \\
\beta \text {-carotene, folate, } \\
\text { vitamins } B 6, C \text { and } E\end{array}$} & \multirow[t]{2}{*}{ Adults } & $\begin{array}{l}\text { High retinol and vitamin } B_{12} \text { intake associated with better } \\
\text { auditory function in women }\end{array}$ & \multirow[t]{2}{*}{ Hercberg et al., 2004 [102] } \\
\hline & & $\begin{array}{l}\text { No associations found for } \beta \text {-carotene, folate and vitamins B6, } \\
\qquad \text { C and E }\end{array}$ & \\
\hline \multirow{3}{*}{$\begin{array}{l}\text { Carotenoids, FA, vitamins } \\
\text { C, A and E }\end{array}$} & \multirow{3}{*}{ Women } & $\begin{array}{c}\text { Inverse correlations between carotenoids ( } \beta \text {-carotene and } \\
\beta \text {-cryptoxanthin) and folate intakes and risk of acquired HL }\end{array}$ & \multirow{3}{*}{ Curhan et al., 2015 [103] } \\
\hline & & $\begin{array}{c}\text { Direct correlation between high vitamin C intake (from } \\
\text { supplements) and risk of HL }\end{array}$ & \\
\hline & & $\begin{array}{l}\text { No significant associations for vitamin A, E, and other } \\
\text { carotenoids }\end{array}$ & \\
\hline \multirow[t]{2}{*}{ Dietary antioxidants } & \multirow[t]{2}{*}{ Adults } & $\begin{array}{l}\text { High vitamin } \mathrm{A} \text { and } \mathrm{E} \text { consumption showed inverse } \\
\text { associations with HL prevalence }\end{array}$ & \multirow{2}{*}{ Gopinath et al., 2011 [93] } \\
\hline & & $\begin{array}{c}\text { Dietary antioxidants consumed alone or in combination were } \\
\text { unable to predict 5-year incidence of ARHL }\end{array}$ & \\
\hline
\end{tabular}


Table 4. Cont.

\begin{tabular}{|c|c|c|c|}
\hline Micronutrient & Study Subjects & Effect & Author and Year \\
\hline Vitamins and minerals & Adults & $\begin{array}{c}\text { Dose-dependent trend between all individual nutrients (except } \\
\text { vitamin E) and better speech pure tone average } \\
\begin{array}{c}\text { Synergistic effect of high intakes of } \beta \text {-carotene and vitamin } C \text { with } \\
\text { magnesium and better pure tone average at high frequencies }\end{array}\end{array}$ & Choi et al.,2014 [94] \\
\hline Folic acid and vitamin $B_{12}$ & Women & $\begin{array}{l}\text { Consistent associations between low vitamin } \mathrm{B}_{12} \text { and folate levels and } \\
\text { ARHL } \\
\begin{array}{c}\text { Stronger association with folate intake rather than with vitamin } \mathrm{B}_{12} \\
\text { ingestion, according to dietary intake }\end{array} \\
\end{array}$ & Houston et al., 1999 [112] \\
\hline Folic acid and vitamin $B_{12}$ & Elderly & $\begin{array}{l}\text { Low serum vitamin levels were significantly associated with HL in } \\
\text { the high frequencies }\end{array}$ & Lasisi et al., 2016 [16] \\
\hline Folic acid and vitamin $B_{12}$ & Adults & $\begin{array}{l}\text { Non-significant associations between serum folate, vitamin } \mathrm{B}_{12}, \mathrm{Hcy} \\
\text { and HL }\end{array}$ & Berner et al., 2000 [113] \\
\hline Folic acid and vitamin $B_{12}$ & Adults & $\begin{array}{c}\text { Low serum folate status increased risk of developing HL } \\
\text { Serum vitamin } B_{12} \text { levels had no association with ARHL } \\
\text { Neither folate nor vitamin } B_{12} \text { showed predictive potential for 5-year } \\
\text { incidence of HL }\end{array}$ & Gopinath et al., 2010 [114] \\
\hline $\begin{array}{l}\text { Folic acid, carotene, } \\
\text { vitamins } C \text { and } E\end{array}$ & Men & $\begin{array}{c}\text { No prospective associations between vitamin } \mathrm{C}, \mathrm{E}, \beta \text {-carotene or } \\
\text { folate consumption and HL } \\
\text { High folate intakes were associated with reduced risk of HL }\end{array}$ & Shargorodsky et al., 2010 [119] \\
\hline Folic acid & Adults & $\begin{array}{c}\text { Adequate folate intake is beneficial for hearing } \\
\text { High folate intake showed non-significant association with an } \\
\text { increased risk of HL }\end{array}$ & Kabagambe et al., 2018 [116] \\
\hline Iron & $\begin{array}{l}\text { Children and } \\
\text { adolescents }\end{array}$ & Increased odds of SNHL in volunteers with iron deficiency anaemia & Schieefer et al., 2017 [119] \\
\hline Iron & Children & $\begin{array}{l}\begin{array}{l}\text { Negative correlation between hemoglobin levels and auditory } \\
\text { function }\end{array} \\
\end{array}$ & Kamel et al., 2016 [121] \\
\hline Iodine & Children & $\begin{array}{l}\text { More severe HL in children with mild-to-moderate iodine deficiency } \\
\text { compared to those with normal iodine levels }\end{array}$ & Valeix et al., 1994 [123] \\
\hline Iodine & Children & $\begin{array}{l}\text { HL prevalences of } 44 \text { to } 15 \% \text { in children with iodine deficiency } \\
\text { compared to } 2 \% \text { in children with adequate levels }\end{array}$ & Azizi et al., 1993 [124] \\
\hline
\end{tabular}

Table 5. Intervention studies to analyze supplementation effect on hearing loss.

\begin{tabular}{|c|c|c|c|}
\hline Micronutrient & Study Subjects & Effect & Author and Year \\
\hline Vitamin A & Preschool children & $\begin{array}{l}\text { Vitamin A supplementation reduced risk of HL } \\
\text { associated with childhood ear infections }\end{array}$ & Schmitz et al., 2012 [105] \\
\hline $\begin{array}{l}\beta \text {-carotene, vitamins } C, \\
\text { E, and magnesium }\end{array}$ & $\begin{array}{c}\text { Boy with } C x 26 \text {-related } \\
\text { HL }\end{array}$ & $\begin{array}{l}\text { Daily supplementation led to no further } \\
\text { progression of HL }\end{array}$ & Thatcher et al., 2014 [97] \\
\hline Iodine & Adults & $\begin{array}{l}\text { Prophylaxis with iodine salt (three years) } \\
\text { revealed an improvement of average hearing } \\
\text { levels, reaching values similar to controls }\end{array}$ & Wang and Yang.1985 [125] \\
\hline Iodine & Children & $\begin{array}{l}\text { Iodine dietary supplementation with ionised } \\
\text { salt led towards a lower auditory threshold }\end{array}$ & Azizi et al.,1993 [126] \\
\hline
\end{tabular}

Finally, a recent study investigated the effect of nicotinamide or vitamin $\mathrm{B}_{3}$ in NIHL. This vitamin is a precursor of $\mathrm{NAD}^{+}$, a cofactor with an important role in the regulation of sirtuins. Animal studies demonstrated that administration of the vitamin, twice daily for 5 days before noise exposure and for $48 \mathrm{~h}$ thereafter, prevented NIHL [122]. Moreover, since the protective effect of nicotinamide in HL is related to its antioxidants properties [122], studies could be also extended to ARHL, therefore opening a new potential line of research in the field of nutrition and auditory function.

\subsection{Minerals and Hearing Loss}

The role of minerals obtained either from dietary sources (Tables 3 and 4) or supplements (Table 5) in the auditory function has been also addressed. Different studies have shown that low iron dietary intakes increase the risk of developing HL. Iron deficiency generates a subset of anaemia in which low hemoglobin, serum ferritin, serum iron, and/or increased soluble transferrin receptor are detected in patients, being oral iron supplementation its usual treatment. Among the pediatric population, premature infants, children exclusively fed with breast milk or formulas without iron fortification, children with reduced dietary intake or poor dietary absorption or those with significant blood 
loss show the highest risk of developing this anaemia. The connection between iron-deficiency anaemia and conductive and SNHL in a cohort of pediatric and adolescent volunteers aged 4-21 years was established by Schieffer et al. [127]. In their study, increased odds of SNHL were found in volunteers with iron deficiency anaemia, hence demonstrating the higher likelihood of these individuals to develop this kind of HL instead of conductive HL. The cochlea only receives blood from the labyrinthine artery, what explains its high susceptibility to the ischemic damage subsequent to iron deficiency anaemia [128]. Often, iron deficiency anaemia is secondary to malnutrition; hence the effect of protein-energy malnutrition and HL was studied in children aged 6-24 months. The data obtained by Kamel and co-workers indicated that $72 \%$ of the volunteers with moderate or severe protein energy malnutrition suffered from anaemia with hemoglobin levels of $9.51 \pm 1.45 \mathrm{~g} / \mathrm{dL}$ as compared to the control group. Moreover, a negative correlation between hemoglobin levels and ABR thresholds was observed, and therefore it was concluded that both protein energy malnutrition and anaemia are risk factors for hearing impairment [129].

The maternal iron nutritional state is crucial for the correct development of the offspring during both pregnancy and lactation. Although this mineral plays an important role in brain development and sensory maturation, including hearing, iron deficiency anaemia is commonly detected in pregnant women, since their increased demand is not fulfilled by the diet. The WHO estimated that this anaemia affected 38\% of the pregnant women in 2011 [130]. Some studies have analyzed the impact of iron deficiency anaemia during pregnancy and lactation in auditory function in guinea pigs. Females received either iron sufficient or deficient diets during gestation, lactation and until the ninth postnatal day, thereafter all animals were fed the sufficient diet [30]. Higher ABR thresholds (worse acuity) were detected in females on the deficient diet at all tone frequencies, indicating that the anaemia affected different parts of the cochlea. The data also showed that iron-deficient pups suffered from SNHL according to the ABR latency-intensive curves, but whether this affectation is temporary or permanent could not be elucidated. However, it was suggested that even if HL disappears in young adulthood, these animals may have a higher risfor presbycusis or other morbidities during aging. The study by Yu et al. evaluated the effect of mild maternal iron deficiency anaemia, using the same regime than in the previous study, in cochlear function of the young guinea pigs, focusing on the putative role of apoptosis [123]. In this case, a significant decrease in the number of cochlear sensory hair cells due to an increase in the number of apoptotic cells was found in iron-deficient animals; this indicates the key role of apoptosis in inhibition of hair cell development, and results in a putatively alteration of the mechanisms underlying cochlear function. In a recent study, these same authors demonstrated that not only caspases (key molecules in the apoptosis cascade), but also other molecules such as prestin, glutamate transporter 3, and myosin VIIa have an important role in HL [123].

The influence of iron levels in HL is not only important in the pediatric population. Therefore, different studies have been carried out in Taiwanese [124] and American [131] adult populations that evaluate the relationship between iron deficiency anaemia and sudden SNHL, which is characterized by a rapid deterioration of hearing function that takes place in less than $72 \mathrm{~h}$. Consistent results indicating a significant relationship between these parameters were found by Chung et al. [132] and Schieffer et al. [131]; noteworthy, SNHL was more severe in individuals under 60 years [124]. However, the underlying mechanism of this association is unclear, although it is thought to be caused by the exacerbation of vascular problems due to iron deficiency anaemia.

Finally, different studies focused on the effect of iodine deficiency and thyroid function in HL [125,133-135]. The relationship between auditory and thyroid function is well known, but has not received much attention until now. A recent review critically analyzes the studies focused on this exciting topic and interested readers are referred to it [134]. Most of the work performed focused on the evaluation of hearing function in patients with congenital and acquired hypothyroidism, whereas only a few analyze the association between mild-to-moderate iodine deficiency and auditory function, especially in children. The population of Guizhou, a province of China with endemic iodine-deficiency, goitre, and cretinism, has poorer average auditory levels than other non-endemic areas making it 
an ideal subject for this type of studies. Three years of prophylaxis with iodine salt, showed an improvement of average hearing levels, reaching values similar to non-endemic controls, as well as recovery of normal thyroid function in the mean while [125]. Later on, Valeix et al. [133] reported more severe HL in children with mild-to-moderate iodine deficiency than in those with normal iodine levels and Azizi et al. [135] reported $44 \%$ and $15 \%$ prevalences in children with iodine deficiency as compared to $2 \%$ in children with adequate levels. These same authors found that dietary supplementation with iodized salt led towards a lower auditory threshold [135]. Hence, the limited data available reinforce the strong need for an in-depth investigation of the effect of iodine supplementation in auditory function at all life stages, including pregnancy, especially considering that thyroid malfunction is increasing lately in Europe.

\section{Other Dietary Factors and Hearing Loss}

The analysis of single nutrients is not always possible and, therefore, different researchers opted to evaluate the overall dietary patterns in HL. Using data from the NHANES study, the relationship between the dietary quality measured with Healthy Eating Index (HEI) and the hearing sensitivity was studied in a population of adults aged 20 to 69 years. A statistically significant inverse correlation between the HEI and pure tone average at high frequencies was detected, being high HEI scores significantly associated with lower hearing thresholds at high frequencies. Although these results do not allow identification of causal relationships, they suggest that healthy eating strategies might benefit patients hearing function and overall life quality [136]. Nevertheless, additional prospective studies are needed for the evaluation of this relationship.

The effect of other dietary components with antioxidant properties has been also investigated for ARHL, NIHL or drug-induced HL. For example, resveratrol, which is a phytoalexin produced by a wide variety of plants with numerous health benefits, including its prominent anti-aging effect, has been used in supplementation studies. Mice on a high caloric diet, when supplemented with resveratrol, extend their lifespan and increase their mitochondrial biogenesis [137]; in this anti-aging effect activation of the sirtuin pathway has a key role. In the auditory system, resveratrol effectively reduced NIHL in F344/NHsd [138] and Wistar albino rats [139], and, additionally, it was reported to protected against cisplatin-dependent ototoxicity, a very interesting way to counteract the adverse effects of this chemotherapy [140]. Other antioxidants, such as caroverine [141] or N-acetyl-L-cysteine [142,143] also have protective effects against NIHL in rats and chinchillas. de Rivera et al. evaluated the effect that a blueberry-enriched diet has in age-related decline of auditory system. Specifically, they used frequency modulated sweeps, which are characterized by changes in frequency over time, in the primary auditory cortex. Aged rats fed blueberry-enriched diet showed faster frequency modulated sweeps, similar than those of young rats, hence confirming the potential of blueberries to reverse ARHL [144].

\section{Conclusions}

The available results suggest that the nutritional status plays an important role in the maintenance of the auditory capacity. Caloric restriction may be an interesting option to avoid HL, as suggested by results obtained in animal models, but extensive human studies are needed to verify this possibility. Additionally, there is an increasing number of data supporting the idea that the concentration of essential macronutrients and micronutrients in our diet has a high impact on the occurrence and progression of HL. The available evidences show that nutritional interventions can prevent, at least partially, this sensorial deficit. In this line, $\omega 3$ fatty acids or dietary antioxidants may be potentially useful as deduced from several epidemiological and animal studies. Nevertheless, the animal models analyzed, and the longitudinal studies carried out to date are still limited to obtain meaningful conclusions. Likewise, studies devoted to the assessment of supplementation with micronutrients, such as vitamins or certain minerals, have provided promising results. Vitamins A and folic acid, as well as minerals such as iodine may offer an alternative to improve HL in a population at risk 
by slowing down the progression of the disorder as deduced from the available studies carried to date. Moreover, data derived specially from animal models have revealed the importance of the genetic background in the outcomes obtained from different dietary patterns and some associations to single nucleotide polymorphisms are emerging in addition to the well-known role of connections in hearing impairments.

Altogether, we can conclude that the efforts carried out to date to uncover the mechanisms involved in the interplay between nutrition and HL have not been in vain, despite the limited, and sometimes contradictory, results available. However, there is a need to deepen into this relationship, particularly as HL is becoming a problem of great magnitude for western countries, due to the demographic change they are experiencing (a substantial increase in their elderly populations). This fact is turning to be of great economic impact, both for the society and the individual, and hence the implementation of preventive protocols, in parallel to the development of effective therapies, seems crucial to improve the quality of life of the whole society.

Author Contributions: A.M.P. and T.P., drafted the manuscript; M.A.P. and G.V.-M. reviewed the manuscript; All authors gave final approval for publication.

Funding: This review was supported by CEU-Banco Santander precompetitive project (MUSPB047) and CEU-Banco Santander consolidation project (MBS18C12) to TP. MINECO (SAF2012-36519) and Instituto de Salud Carlos III (RETIC ARADyAL RD 16/0006/0021) supported MAP contributions.

Acknowledgments: The authors thank Isabel Varela-Nieto for helpful discussions. The authors also thank Javier Pérez (IIBM, CSIC-UAM) for the technical support provided.

Conflicts of Interest: The authors declare no conflict of interest.

\section{References}

1. Dror, A.A.; Avraham, K.B. Hearing loss: Mechanisms revealed by genetics and cell biology. Annu. Rev. Genet. 2009, 43, 411-437. [CrossRef] [PubMed]

2. Roth, T.N.; Hanebuth, D.; Probst, R. Prevalence of age-related hearing loss in Europe: A review. Eur. Arch. Otorhinolaryngol. 2011, 268, 1101-1107. [CrossRef] [PubMed]

3. World Health Organization (WHO). Childhood Hearing Loss: Strategies for Prevention and Care; World Health Organization: Geneva, Switzerland, 2016.

4. Deafness and Hearing Loss. Available online: http://www.who.int/news-room/fact-sheets/detail/ deafness-and-hearing-loss (accessed on 15 October 2018).

5. Li-Korotky, H.S. Age-related hearing loss: Quality of care for quality of life. Gerontologist 2012, 52, $265-271$. [CrossRef]

6. TARGEAR NEWSLETTER JUNE 2017: About the Presbycusis. Available online: http:/ / targear.eu/targearnewsletter-june-2017/ (accessed on 22 November 2018).

7. Editorial Board. Hearing loss: Time for sound action. The Lancet 2017, 390, 2414. [CrossRef]

8. Wilson, B.S.; Tucci, D.L.; Merson, M.H.; O’Donoghue, G.M. Global hearing health care: New findings and perspectives. Lancet 2017, 390, 2503-2515. [CrossRef]

9. Emmett, S.D.; West, K.P., Jr. Nutrition and hearing loss: A neglected cause and global health burden. Am. J. Clin. Nutr. 2015, 102, 987-988. [CrossRef] [PubMed]

10. Ciorba, A.; Bianchini, C.; Pelucchi, S.; Pastore, A. The impact of hearing loss on the quality of life of elderly adults. Clin. Interv. Aging 2012, 7, 159-163. [CrossRef] [PubMed]

11. Cunningham, L.L.; Tucci, D.L. Hearing Loss in Adults. N. Engl. J. Med. 2017, 377, 2465-2473. [CrossRef] [PubMed]

12. World Health Organization (WHO). Global Costs of Unaddressed Hearing Loss and Cost-Effectiveness of Interventions: A WHO Report; World Health Organization: Geneva, Switzerland, 2017.

13. Crowson, M.G.; Hertzano, R.; Tucci, D.L. Emerging Therapies for Sensorineural Hearing Loss. Otol. Neurotol. 2017, 38, 792-803. [CrossRef]

14. World Health Organization (WHO). Multi-Country Assessment of National Capacity to Provide Hearing Care; World Health Organization: Geneva, Switzerland, 2013. 
15. Karli, R.; Gül, A.; Uğur, B. Effect of vitamin B12 deficiency on otoacoustic emissions. Acta Otorhinolaryngol. Ital. 2013, 33, 243-247.

16. Lasisi, A.O.; Fehintola, F.A.; Yusuf, O.B. Age-related hearing loss, vitamin B12, and folate in the elderly. Otolaryngol. Head Neck Surg. 2010, 143, 826-830. [CrossRef] [PubMed]

17. Cadoni, G.; Agostino, S.; Scipione, S.; Galli, J. Low serum folate levels: A risk factor for sudden sensorineural hearing loss? Acta Otolaryngol. 2004, 124, 608-611. [CrossRef] [PubMed]

18. Gok, U.; Halifeoglu, I.; Canatan, H.; Yildiz, M.; Gursu, M.F.; Gur, B. Comparative analysis of serum homocysteine, folic acid and Vitamin B12 levels in patients with noise-induced hearing loss. Auris Nasus Larynx 2004, 31, 19-22. [CrossRef] [PubMed]

19. Rosen, S.; Olin, P.; Rosen, H.V. Diery prevention of hearing loss. Acta Otolaryngol. 1970, 70, $242-247$. [CrossRef] [PubMed]

20. Dullemeijer, C.; Verhoef, P.; Brouwer, I.A.; Kok, F.J.; Brummer, R.J.; Durga, J. Plasma very long-chain n-3 polyunsaturated fatty acids and age-related hearing loss in older adults. J. Nutr. Health Aging 2010, 14, 347-351. [CrossRef]

21. Gopinath, B.; Flood, V.M.; Rochtchina, E.; McMahon, C.M.; Mitchell, P. Consumption of omega-3 fatty acids and fish and risk of age-related hearing loss. Am. J. Clin. Nutr. 2010, 92, 416-421. [CrossRef]

22. Shargorodsky, J.; Curhan, S.G.; Henderson, E.; Eavey, R.; Curhan, G.C. Heavy metals exposure and hearing loss in US adolescents. Arch Otolaryngol. Head Neck Surg. 2011, 137, 1183-1189. [CrossRef]

23. Magariños, M.; Contreras, J.; Aburto, M.R.; Varela-Nieto, I. Early development of the vertebrate inner ear. Anat. Rec. (Hoboken) 2012, 295, 1775-1790. [CrossRef]

24. Magariños, M.; Contreras, J.; Varela-Nieto, I. Early development of the vertebrate inner ear. In Development of the Auditory and Vestibular Systems; Romand, R., Varela-NIeto, I., Eds.; Elservier: Amsterdam, The Netherlands, 2014; pp. 1-30.

25. Sanchez-Calderon, H.; Rodriguez-de la Rosa, L.; Milo, M.; Pichel, J.G.; Holley, M.; Varela-Nieto, I. RNA microarray analysis in prenatal mouse cochlea reveals novel IGF-I target genes: Implication of MEF2 and FOXM1 transcription factors. PLoS ONE 2010, 5, e8699. [CrossRef]

26. Rivera, T.; Sanz, L.; Camarero, G.; Varela-Nieto, I. Drug delivery to the inner ear: Strategies and their therapeutic implications for sensorineural hearing loss. Curr. Drug Deliv. 2012, 9, 231-242. [CrossRef]

27. Clark, J.G. Uses and abuses of hearing loss classification. ASHA 1981, 23, 493-500. [PubMed]

28. Manrique, M.; Ramos, A.; Morera, C.; Cenjor, C.; Lavilla, M.J.; Boleas, M.S.; Cervera-Paz, F.J. Analysis of the cochlear implant as a treatment technique for profound hearing loss in pre and postlocutive patients. Acta Otorrinolaringol. Esp. 2006, 57, 2-23. [CrossRef]

29. Cediel, R.; Riquelme, R.; Contreras, J.; Díaz, A.; Varela-Nieto, I. Sensorineural hearing loss in insulin-like growth factor I-null mice: A new model of human deafness. Eur. J. Neurosci. 2006, 23, 587-590. [CrossRef]

30. Jougleux, J.L.; Rioux, F.M.; Church, M.W.; Fiset, S.; Surette, M.E. Mild maternal iron deficiency anemia during pregnancy and lactation in guinea pigs causes abnormal auditory function in the offspring. J. Nutr. 2011, 141, 1390-1395. [CrossRef] [PubMed]

31. Nandi, S.S.; Dhatrak, S.V. Occupational noise-induced hearing loss in India. Indian J. Occup. Environ. Med. 2008, 12, 53-56. [CrossRef] [PubMed]

32. Lanvers-Kaminsky, C.; Zehnhoff-Dinnesen, A.A.; Parfitt, R.; Ciarimboli, G. Drug-induced ototoxicity: Mechanisms, Pharmacogenetics, and protective strategies. Clin. Pharmacol. Ther. 2017, 101, 491-500. [CrossRef]

33. Cruickshanks, K.J.; Tweed, T.S.; Wiley, T.L.; Klein, B.E.; Klein, R.; Chappell, R.; Nondahl, D.M.; Dalton, D.S. The 5-year incidence and progression of hearing loss: The epidemiology of hearing loss study. Arch Otolaryngol. Head Neck Surg. 2003. [CrossRef] [PubMed]

34. Yamasoba, T.; Lin, F.R.; Someya, S.; Kashio, A.; Sakamoto, T.; Kondo, K. Current concepts in age-related hearing loss: Epidemiology and mechanistic pathways. Hear Res. 2013, 303, 30-38. [CrossRef]

35. Shearer, A.E.; Hildebrand, M.S.; Sloan, C.M.; Smith, R.J. Deafness in the genomics era. Hear Res. 2011, 282, 1-9. [CrossRef]

36. Shearer, A.E.; Hildebrand, M.S.; Smith, R.J.H. Hereditary Hearing Loss and Deafness Overview. In Gene Reviews; Adam, M.P., Pagon, R.A., Wallace, S.E., Bean, L.J.H., Stephens, K., Amemiya, A., Eds.; GeneReviews®: Seattle, WA, USA, 1999. 
37. Agrawal, Y.; Platz, E.A.; Niparko, J.K. Prevalence of hearing loss and differences by demographic characteristics among US adults: Data from the National Health and Nutrition Examination Survey, 1999-2004. Arch Intern. Med. 2008, 168, 1522-1530. [CrossRef]

38. Yang, C.H.; Schrepfer, T.; Schacht, J. Age-related hearing impairment and the triad of acquired hearing loss. Front. Cell. Neurosci. 2015. [CrossRef] [PubMed]

39. Dawes, P.; Cruickshanks, K.J.; Moore, D.R.; Edmondson-Jones, M.; McCormack, A.; Fortnum, H.; Munro, K.J. Cigarette smoking, passive smoking, alcohol consumption, and hearing loss. J. Assoc. Res. Otolaryngol. 2014, 15, 663-674. [CrossRef] [PubMed]

40. Fransen, E.; Topsakal, V.; Hendrickx, J.J.; Van Laer, L.; Huyghe, J.R.; Van Eyken, E.; Lemkens, N.; Hannula, S.; Mäki-Torkko, E.; Jensen, M.; et al. Occupational noise, smoking, and a high body mass index are risk factors for age-related hearing impairment and moderate alcohol consumption is protective: A European population-based multicenter study. J. Assoc. Res. Otolaryngol. 2008, 9, 264-276. [CrossRef] [PubMed]

41. DeCarlo, C.A.; HA, T.; Williams, D.; Dixon, R.A.; MacDonald, S.W. BioAge: Toward a multi-determined, mechanistic account of cognitive aging. Aging Res. Rev. 2014, 18, 95-105. [CrossRef] [PubMed]

42. López-Otín, C.; Blasco, M.A.; Partridge, L.; Serrano, M.; Kroemer, G. The hallmarks of aging. Cell 2013, 153, 1194-1217. [CrossRef] [PubMed]

43. Liu, X.Z.; Yan, D. Aging and hearing loss. J. Pathol. 2007, 211, 188-197. [CrossRef] [PubMed]

44. Desai, M.; Pratt, L.A.; Lentzner, H.; Robinson, K.N. Trends in vision and hearing among older Americans. Aging Trends 2001, 2, 1-8.

45. Liberman, M.C. Noise-induced and age-related hearing loss: New perspectives and potential therapies. F1000Research 2017, 6, 927. [CrossRef]

46. Someya, S.; Yu, W.; Hallows, W.C.; Xu, J.; Vann, J.M.; Leeuwenburgh, C.; Tanokura, M.; Denu, J.M.; Prolla, T.A. Sirt3 mediates reduction of oxidative damage and prevention of age-related hearing loss under caloric restriction. Cell 2010, 143, 802-812. [CrossRef]

47. Lee, F.S.; Matthews, L.J.; Dubno, J.R.; Mills, J.H. Longitudinal study of pure-tone thresholds in older persons. Ear Hear. 2005, 26, 1-11. [CrossRef]

48. Le Prell, C.G.; Yamashita, D.; Minami, S.B.; Yamasoba, T.; Miller, J.M. Mechanisms of noise-induced hearing loss indicate multiple methods of prevention. Hear. Res. 2007, 226, 22-43. [CrossRef] [PubMed]

49. Darrat, I.; Ahmad, N.; Seidman, K.; Seidman, M.D. Auditory research involving antioxidants. Curr. Opin. Otolaryngol. Head Neck Surg. 2007, 15, 358-363. [CrossRef] [PubMed]

50. World Health Organization. World Report on Aging and Health; World Health Organization: Luxembourg, 2015.

51. Balasubramanian, P.; Howell, P.R.; Anderson, R.M. Aging and Caloric Restriction Research: A Biological Perspective with Translational Potential. EBioMedicine 2017, 21, 37-44. [CrossRef] [PubMed]

52. O'Flanagan, C.H.; Smith, L.A.; McDonell, S.B.; Hursting, S.D. When less may be more: Calorie restriction and response to cancer therapy. BMC Med. 2017, 15, 106. [CrossRef] [PubMed]

53. Fontana, L.; Partridge, L.; Longo, V.D. Extending healthy life span-from yeast to humans. Science 2010, 328, 321-326. [CrossRef]

54. Fujimoto, C.; Yamasoba, T. Oxidative stresses and mitochondrial dysfunction in age-related hearing loss. Oxid. Med. Cell. Longev. 2014, 2014. [CrossRef] [PubMed]

55. Han, C.; Someya, S. Maintaining good hearing: Calorie restriction, Sirt3, and glutathione. Exp. Gerontol. 2013, 48, 1091-1095. [CrossRef]

56. Speakman, J.R.; Mitchell, S.E. Caloric restriction. Mol. Aspects Med. 2011, 32, 159-221. [CrossRef]

57. Mannström, P.; Ulfhake, B.; Kirkegaard, M.; Ulfendahl, M. Dietary restriction reduces age-related degeneration of stria vascularis in the inner ear of the rat. Exp. Gerontol. 2013, 48, 1173-1179. [CrossRef]

58. Hirschey, M.D.; Shimazu, T.; Goetzman, E.; Jing, E.; Schwer, B.; Lombard, D.B.; Grueter, C.A.; Harris, C.; Biddinger, S.; Ilkayeva, O.R.; et al. SIRT3 regulates mitochondrial fatty-acid oxidation by reversible enzyme deacetylation. Nature 2010, 464, 121-125. [CrossRef]

59. Sundaresan, N.R.; Samant, S.A.; Pillai, V.B.; Rajamohan, S.B.; Gupta, M.P. SIRT3 is a stress-responsive deacetylase in cardiomyocytes that protects cells from stress-mediated cell death by deacetylation of Ku70. Mol. Cell Biol. 2008, 28, 6384-6401. [CrossRef] [PubMed] 
60. Someya, S.; Yamasoba, T.; Weindruch, R.; Prolla, T.A.; Tanokura, M. Caloric restriction suppresses apoptotic cell death in the mammalian cochlea and leads to prevention of presbycusis. Neurobiol. Aging 2007, 28, 1613-1622. [CrossRef] [PubMed]

61. Someya, S.; Tanokura, M.; Weindruch, R.; Prolla, T.A.; Yamasoba, T. Effects of caloric restriction on age-related hearing loss in rodents and rhesus monkeys. Curr. Aging Sci. 2010, 3, 20-25. [CrossRef] [PubMed]

62. Fowler, C.G.; Torre, P., III; Kemnitz, J.W. Effects of caloric restriction and aging on the auditory function of rhesus monkeys (Macaca mulatta): The University of Wisconsin study. Hear. Res. 2002, 169, 24-35. [CrossRef]

63. Ramsey, J.J.; Colman, R.J.; Binkley, N.C.; Christensen, J.D.; Gresl, T.A.; Kemnitz, J.W.; Weindruch, R. Dietary restriction and aging in rhesus monkeys: The University of Wisconsin study. Exp. Gerontol. 2000, 35, 1131-1149. [CrossRef]

64. Torre, P., III; Mattison, J.A.; Fowler, C.G.; Lane, M.A.; Roth, G.S.; Ingram, D.K. Assessment of auditory function in rhesus monkeys (Macaca mulatta): Effects of age and calorie restriction. Neurobiol. Aging 2004, 25, 945-954. [CrossRef] [PubMed]

65. Fowler, C.G.; Chiasson, K.B.; Leslie, T.H.; Thomas, D.; Beasley, T.M.; Kemnitz, J.W.; Weindruch, R. Auditory function in rhesus monkeys: Effects of aging and caloric restriction in the Wisconsin monkeys five years later. Hear. Res. 2010, 261, 75-81. [CrossRef] [PubMed]

66. Rippe, J.M.; Sievenpiper, J.L.; Lê, K.A.; White, J.S.; Clemens, R.; Angelopoulos, T.J. What is the appropriate upper limit for added sugars consumption? Nutr. Rev. 2017, 75, 18-36. [CrossRef]

67. Xi, B.; Huang, Y.; Reilly, K.H.; Li, S.; Zheng, R.; Barrio-Lopez, M.T.; Martinez-Gonzalez, M.A.; Zhou, D. Sugar-sweetened beverages and risk of hypertension and CVD: A dose-response meta-analysis. Br. J. Nutr. 2015, 113, 709-717. [CrossRef]

68. Gopinath, B.; Flood, V.M.; McMahon, C.M.; Burlutsky, G.; Brand-Miller, J.; Mitchell, P. Dietary glycemic load is a predictor of age-related hearing loss in older adults. J. Nutr. 2010, 140, 2207-2212. [CrossRef]

69. Tachibana, N.; Iwaoka, Y.; Hirotsuka, M.; Horio, F.; Kohno, M. Beta-conglycinin lowers very-low-density lipoprotein-triglyceride levels by increasing adiponectin and insulin sensitivity in rats. Biosci. Biotechnol. Biochem. 2010, 74, 1250-1255. [CrossRef] [PubMed]

70. Tanigawa, T.; Shibata, R.; Kondo, K.; Katahira, N.; Kambara, T.; Inoue, Y.; Nonoyama, H.; Horibe, Y.; Ueda, H.; Murohara, T. Soybean $\beta$-Conglycinin Prevents Age-Related Hearing Impairment. PLoS ONE 2015, 10, e0137493. [CrossRef] [PubMed]

71. Rosen, S.; Olin, P. Hearing loss and coronary heart disease. Bull. N. Y. Acad. Med. 1965, 41, 1052-1068. [CrossRef] [PubMed]

72. Fusconi, M.; Chistolini, A.; de Virgilio, A.; Greco, A.; Massaro, F.; Turchetta, R.; Benincasa, A.T.; Tombolini, M.; de Vincentiis, M. Sudden sensorineural hearing loss: A vascular cause? Analysis of prothrombotic risk factors in head and neck. Int. J. Audiol. 2012, 51, 800-805. [CrossRef] [PubMed]

73. Wang, C.; Harris, W.S.; Chung, M.; Lichtenstein, A.H.; Balk, E.M.; Kupelnick, B.; Jordan, H.S.; Lau, J. n-3 Fatty acids from fish or fish-oil supplements, but not alpha-linolenic acid, benefit cardiovascular disease outcomes in primary- and secondary-prevention studies: A systematic review. Am. J. Clin. Nutr. 2006, 84, 5-17. [CrossRef] [PubMed]

74. Bhattacharya, A.; Sun, D.; Rahman, M.; Fernandes, G. Different ratios of eicosapentaenoic and docosahexaenoic omega-3 fatty acids in commercial fish oils differentially alter pro-inflammatory cytokines in peritoneal macrophages from C57BL/6 female mice. J. Nutr. Biochem. 2007, 18, 23-30. [CrossRef]

75. Gates, G.A.; Cobb, J.L.; D'Agostino, R.B.; Wolf, P.A. The relation of hearing in the elderly to the presence of cardiovascular disease and cardiovascular risk factors. Arch Otolaryngol. Head Neck Surg. 1993, 119, 156-161. [CrossRef]

76. Gratton, M.A.; Schulte, B.A. Alterations in microvasculature are associated with atrophy of the stria vascularis in quiet-aged gerbils. Hear. Res. 1995, 82, 44-52. [CrossRef]

77. Durga, J.; Verhoef, P.; Anteunis, L.J.; Schouten, E.; Kok, F.J. Effects of folic acid supplementation on hearing in older adults: A randomized, controlled trial. Ann. Intern. Med. 2007, 146, 1-9. [CrossRef]

78. Curhan, S.G.; Eavey, R.D.; Wang, M.; Rimm, E.B.; Curhan, G.C. Fish and fatty acid consumption and the risk of hearing loss in women. Am. J. Clin. Nutr. 2014, 100, 1371-1377. [CrossRef]

79. Péneau, S.; Jeandel, C.; Déjardin, P.; Andreeva, V.A.; Hercberg, S.; Galan, P.; Kesse-Guyot, E. Intake of specific nutrients and foods and hearing level measured 13 years later. Br. J. Nutr. 2013, 109, 2079-2088. [CrossRef] 
80. Church, M.W.; Jen, K.L.; Anumba, J.I.; Jackson, D.A.; Adams, B.R.; Hotra, J.W. Excess omega-3 fatty acid consumption by mothers during pregnancy and lactation caused shorter life span and abnormal ABRs in old adult offspring. Neurotoxicol. Teratol. 2010, 32, 171-181. [CrossRef] [PubMed]

81. Piolot, A.; Blache, D.; Boulet, L.; Fortin, L.J.; Dubreuil, D.; Marcoux, C.; Davignon, J.; Lussier-Cacan, S. Effect of fish oil on LDL oxidation and plasma homocysteine concentrations in health. J. Lab. Clin. Med. 2003, 141, 41-49. [CrossRef]

82. Huang, T.; Zheng, J.; Chen, Y.; Yang, B.; Wahlqvist, M.L.; Li, D. High consumption of $\Omega-3$ polyunsaturated fatty acids decrease plasma homocysteine: A meta-analysis of randomized, placebo-controlled trials. Nutrition 2011, 27, 863-867. [CrossRef] [PubMed]

83. Martínez-Vega, R.; Partearroyo, T.; Vallecillo, N.; Varela-Moreiras, G.; Pajares, M.A.; Varela-Nieto, I. Long-term omega-3 fatty acid supplementation prevents expression changes in cochlear homocysteine metabolism and ameliorates progressive hearing loss in C57BL/6J mice. J. Nutr. Biochem. 2015, 26, 1424-1433. [CrossRef] [PubMed]

84. Saito, T.; Sato, K.; Saito, H. An experimental study of auditory dysfunction associated with hyperlipoproteinemia. Arch Otorhinolaryngol. 1986, 243, 242-245. [CrossRef]

85. Sikora, M.A.; Morizono, T.; Ward, W.D.; Paparella, M.M.; Leslie, K. Diet-induced hyperlipidemia and auditory dysfunction. Acta Otolaryngol. 1986, 102, 372-381. [CrossRef]

86. Gopinath, B.; Flood, V.M.; Teber, E.; McMahon, C.M.; Mitchell, P. Dietary intake of cholesterol is positively associated and use of cholesterol-lowering medication is negatively associated with prevalent age-related hearing loss. J. Nutr. 2011, 141, 1355-1361. [CrossRef]

87. Tokgöz, S.A.; Vuralkan, E.; Sonbay, N.D.; Çalişkan, M.; Saka, C.; Beşalti, Ö.İ.A. Protective effects of vitamins $\mathrm{E}, \mathrm{B}$ and $\mathrm{C}$ and L-carnitine in the prevention of cisplatin-induced ototoxicity in rats. J. Laryngol. Otol. 2012, 126, 464-469. [CrossRef]

88. McFadden, S.L.; Woo, J.M.; Michalak, N.; Ding, D. Dietary vitamin C supplementation reduces noise-induced hearing loss in guinea pigs. Hear. Res. 2005, 202, 200-208. [CrossRef]

89. Evans, P.; Halliwell, B. Free radicals and hearing. Cause, consequence, and criteria. Ann. N. Y. Acad. Sci. 1999, 884, 19-40. [CrossRef]

90. Schafer, F.Q.; Wang, H.P.; Kelley, E.E.; Cueno, K.L.; Martin, S.M.; Buettner, G.R. Comparing beta-carotene, vitamin E and nitric oxide as membrane antioxidants. Biol. Chem. 2002, 383, 671-681. [CrossRef]

91. Le Prell, C.G.; Hughes, L.F.; Miller, J.M. Free radical scavengers vitamins A, C, and E plus magnesium reduce noise trauma. Free Radic. Biol. Med. 2007, 42, 1454-1463. [CrossRef]

92. Heman-Ackah, S.E.; Juhn, S.K.; Huang, T.C.; Wiedmann, T.S. A combination antioxidant therapy prevents age-related hearing loss in C57BL/ 6 mice. Otolaryngol. Head Neck Surg. 2010, 143, 429-434. [CrossRef]

93. Gopinath, B.; Flood, V.M.; McMahon, C.M.; Burlutsky, G.; Spankovich, C.; Hood, L.J.; Mitchell, P. Dietary antioxidant intake is associated with the prevalence but not incidence of age-related hearing loss. J. Nutr. Health Aging. 2011, 15, 896-900. [CrossRef]

94. Choi, Y.H.; Miller, J.M.; Tucker, K.L.; Hu, H.; Park, S.K. Antioxidant vitamins and magnesium and the risk of hearing loss in the US general population. Am. J. Clin. Nutr. 2014, 99, 148-155. [CrossRef]

95. Green, K.L.; Swiderski, D.L.; Prieskorn, D.M.; DeRemer, S.J.; Beyer, L.A.; Miller, J.M.; Green, G.E.; Raphael, Y. ACEMg Diet Supplement Modifies Progression of Hereditary Deafness. Sci. Rep. W. 2016, 6. [CrossRef]

96. Cohen-Salmon, M.; Ott, T.; Michel, V.; Hardelin, J.P.; Perfettini, I.; Eybalin, M.; Wu, T.; Marcus, D.C.; Wangemann, P.; Willecke, K.; et al. Targeted ablation of connexin26 in the inner ear epithelial gap junction network causes hearing impairment and cell death. Curr. Biol. 2002, 12, 1106-1111. [CrossRef]

97. Thatcher, A.; Le Prell, C.; Miller, J.; Green, G. ACEMg supplementation ameliorates progressive Connexin 26 hearing loss in a child. Int. J. Pediatr. Otorhinolaryngol. 2014, 78, 563-565. [CrossRef]

98. Kang, J.W.; Choi, H.S.; Kim, K.; Choi, J.Y. Dietary vitamin intake correlates with hearing thresholds in the older population: The Korean National Health and Nutrition Examination Survey. Am. J. Clin. Nutr. 2014, 99, 1407-1413. [CrossRef]

99. Thomas, D.R. Vitamins in aging, health, and longevity. Clin Interv Aging 2006, 1, 81-91. [CrossRef]

100. Carpinelli, M.R.; Wise, A.K.; Burt, R.A. Vitamin D-deficient diet rescues hearing loss in Klotho mice. Hear. Res. 2011, 275, 105-109. [CrossRef] 
101. Michikawa, T.; Nishiwaki, Y.; Asakura, K.; Hillebrand, G.; Miyamoto, K.; Ono, M.; Kinjo, Y.; Akiba, S.; Takebayashi, T. Sunlight exposure may be a risk factor of hearing impairment: A community-based study in Japanese older men and women. J. Gerontol. A. Biol. Sci. Med. Sci. 2013, 68, 96-103. [CrossRef]

102. Hercberg, S.; Galan, P.; Preziosi, P.; Bertrais, S.; Mennen, L.; Malvy, D.; Roussel, A.M.; Favier, A.S.B. The SU.VI.MAX Study: A randomized, placebo-controlled trial of the health effects of antioxidant vitamins and minerals. Arch Intern. Med. 2004, 164, 2335-2342. [CrossRef]

103. Curhan, S.G.; Stankovic, K.M.; Eavey, R.D.; Wang, M.; Stampfer, M.J.; Curhan, G.C. Carotenoids, vitamin A, vitamin C, vitamin E, and folate and risk of self-reported hearing loss in women. Am. J. Clin. Nutr. 2015, 102, 1167-1175. [CrossRef]

104. Romand, R.; Dollé, P.; Hashino, E. Retinoid signaling in inner ear development. J. Neurobiol. 2006, 66, 687-704. [CrossRef]

105. Schmitz, J.; West, K.P., Jr.; Khatry, S.K.; Wu, L.; Leclerq, S.C.; Karna, S.L.; Katz, J.; Sommer, A.; Pillion, J.W. Vitamin A supplementation in preschool children and risk of hearing loss as adolescents and young adults in rural Nepal: Randomised trial cohort follow-up study. BMJ 2012, 344. [CrossRef]

106. Emmett, S.D.; West, K.P., Jr. Gestational vitamin A deficiency: A novel cause of sensorineural hearing loss in the developing world? Med. Hypotheses. 2014, 82, 6-10. [CrossRef]

107. Green, R.; Allen, L.H.; Bjørke-Monsen, A.L.; Brito, A.; Guéant, J.L.; Miller, J.W.; Molloy, A.M.; Nexo, E.; Stabler, S.; Toh, B.H.; et al. Vitamin B12 deficiency. Nat. Rev. Dis. Primers. 2017, 3. [CrossRef]

108. Ubbink, J.B.; Vermaak, W.J.; van der Merwe, A.; Becker, P.J. Vitamin B-12, vitamin B-6, and folate nutritional status in men with hyperhomocysteinemia. Am. J. Clin. Nutr. 1993, 57, 47-53. [CrossRef]

109. Partearroyo, T.; Vallecillo, N.; Pajares, M.A.; Varela-Moreiras, G.I.V.-N. Cochlear Homocysteine Metabolism at the Crossroad of Nutrition and Sensorineural Hearing Loss. Front. Mol. Neurosci. 2017, 10. [CrossRef]

110. Park, S.; Johnson, M.A.; Shea-Miller, K.; De Chicchis, A.R.; Allen, R.H.; Stabler, S.P. Age-related hearing loss, methylmalonic acid, and vitamin B12 status in older adults. J. Nutr. Elder. 2006, 25, 105-120. [CrossRef]

111. Berkiten, G.; Yildirim, G.; Topaloglu, I.; Ugras, H. Vitamin B12 levels in patients with tinnitus and effectiveness of vitamin B12 treatment on hearing threshold and tinnitus. B-ENT. 2013, 9, 111-116.

112. Kundu, S.M.C.; Tyagi, N.; Sen, U.; Tyagi, A.C.; Tyagi, S.C. Folic acid improves inner ear vascularization in hyperhomocysteinemic mice. Hear. Res. 2012, 284, 42-51. [CrossRef]

113. Martínez-Vega, R.; Garrido, F.; Partearroyo, T.; Cediel, R.; Zeisel, S.H.; Martínez-Álvarez, C.; Varela-Moreiras, G.; Varela-Nieto, I.; Pajares, M.A. Folic acid deficiency induces premature hearing loss through mechanisms involving cochlear oxidative stress and impairment of homocysteine metabolism. FASEB J. 2015, 29, 418-432. [CrossRef]

114. Martínez-Vega, R.; Murillo-Cuesta, S.; Partearroyo, T.; Varela-Moreiras, G.; Varela-Nieto, I.; Pajares, M.A. Long-Term Dietary Folate Deficiency Accelerates Progressive Hearing Loss on CBA/Ca Mice. Front. Aging Neurosci. 2016, 8. [CrossRef]

115. Manche, S.K.; Jangala, M.; Dudekula, D.; Koralla, M.; Akka, J. Polymorphisms in folate metabolism genes are associated with susceptibility to presbycusis. Life Sci. 2018, 196, 77-83. [CrossRef]

116. Houston, D.K.; Johnson, M.A.; Nozza, R.J.; Gunter, E.W.; Shea, K.J.; Cutler, G.M.; Edmonds, J.T. Age-related hearing loss, vitamin B-12, and folate in elderly women. Am. J. Clin. Nutr. 1999, 69, 564-571. [CrossRef]

117. Berner, B.; Odum, L.; Parving, A. Age-related hearing impairment and B vitamin status. Acta Otolaryngol. 2000, 120, 633-637. [CrossRef]

118. Gopinath, B.; Flood, V.M.; Rochtchina, E.; McMahon, C.M.; Mitchell, P. Serum homocysteine and folate concentrations are associated with prevalent age-related hearing loss. J. Nutr. 2010, 140, 1469-1474. [CrossRef]

119. Shargorodsky, J.; Curhan, S.G.; Eavey, R.; Curhan, G.C. A prospective study of vitamin intake and the risk of hearing loss in men. Otolaryngol. Head Neck Surg. 2010, 142, 231-236. [CrossRef]

120. Kabagambe, E.K.; Lipworth, L.; Labadie, R.F.; Hood, L.J.; Francis, D.O. Erythrocyte folate, serum vitamin B12, and hearing loss in the 2003-2004 National Health And Nutrition Examination Survey (NHANES). Eur. J. Clin. Nutr. 2018, 72, 720-727. [CrossRef]

121. Shah, T.; Joshi, K.; Mishra, S.; Otiv, S.; Kumbar, V. Molecular and cellular effects of vitamin B12 forms on human trophoblast cells in presence of excessive folate. Biomed. Pharmacother. 2016, 84, 526-534. [CrossRef] 
122. Brown, K.D.; Maqsood, S.; Huang, J.Y.; Pan, Y.; Harkcom, W.; Li, W.; Sauve, A.; Verdin, E.; Jaffrey, S.R. Activation of SIRT3 by the $\mathrm{NAD}^{+}$precursor nicotinamide riboside protects from noise-induced hearing loss. Cell Metab. 2014, 20, 1059-1068. [CrossRef]

123. Yu, F.; Hao, S.; Zhao, Y.; Ren, Y.; Yang, J.; Sun, X.; Chen, J. Mild maternal iron deficiency anemia induces DPOAE suppression and cochlear hair cell apoptosis by caspase activation in young guinea pigs. Environ. Toxicol. Pharmacol 2014, 37, 291-299. [CrossRef]

124. Chung, S.D.; Chen, P.Y.; Lin, H.C.; Hung, S.H. Sudden sensorineural hearing loss associated with iron-deficiency anemia: A population-based study. JAMA Otolaryngol. Head Neck Surg. 2014, 140, 417-422. [CrossRef]

125. Wang, Y.Y.; Yang, S.H. Improvement in hearing among otherwise normal schoolchildren in iodine-deficient areas of Guizhou, China, following use of iodized salt. Lancet 1985, 2, 518-520.

126. Azizi, F.; Kalani, H.; Kimiagar, M.; Ghazi, A.; Sarshar, A.; Nafarabadi, M.; Rahbar, N.; Noohi, S.; Mohajer, M.; Yassai, M. Physical, neuromotor and intellectual impairment in non-cretinous schoolchildren with iodine deficiency. Int. J. Vitam. Nutr. Res. 1995, 65, 199-205.

127. Schieffer, K.M.; Connor, J.R.; Pawelczyk, J.A.; Sekhar, D.L. The Relationship between Iron Deficiency Anemia and Sensorineural Hearing Loss in the Pediatric and Adolescent Population. Am. J. Audiol. 2017, 26, 155-162. [CrossRef]

128. Lemajić-Komazec, S.; Abenavoli, L. Iron deficiency anemia and hearing loss. Int. J. Pediatr. Otorhinolaryngol. 2017, 1, S655-S876. [CrossRef]

129. Kamel, T.B.; Deraz, T.E.; Elkabarity, R.H.; Ahmed, R.K. Protein energy malnutrition associates with different types of hearing impairments in toddlers: Anemia increases cochlear dysfunction. Int. J. Pediatr. Otorhinolaryngol. 2016, 85, 27-31. [CrossRef] [PubMed]

130. World Health Organization (WHO). The Global Prevalence of Anaemia in 2011; World Health Organization: Geneva, Switzerland, 2015.

131. Schieffer, K.M.; Chuang, C.H.; Connor, J.; Pawelczyk, J.A.; Sekhar, D.L. Association of Iron Deficiency Anemia With Hearing Loss in US Adults. JAMA Otolaryngol. Head Neck Surg. 2017, 143, 350-354. [CrossRef] [PubMed]

132. Sun, A.H.; Xiao, S.Z.; Li, B.S.; Li, Z.J.; Wang, T.Y.; Zhang, Y.S. Iron deficiency and hearing loss. Experimental study in growing rats. ORL J. Otorhinolaryngol. Relat. Spec. 1987, 49, 118-122. [CrossRef] [PubMed]

133. Valeix, P.; Preziosi, P.; Rossignol, C.; Farnier, M.A.; Hercberg, S. Relationship between urinary iodine concentration and hearing capacity in children. Eur. J. Clin. Nutr. 1994, 48, 54-59. [PubMed]

134. Melse-Boonstra, A.; Mackenzie, I. Iodine deficiency, thyroid function and hearing deficit: A review. Nutr. Res. Rev. 2013, 26, 110-117. [CrossRef] [PubMed]

135. Azizi, F.; Sarshar, A.; Nafarabadi, M.; Ghazi, A.; Kimiagar, M.; Noohi, S.; Rahbar, N.; Bahrami, A.; Kalantari, S. Impairment of neuromotor and cognitive development in iodine-deficient schoolchildren with normal physical growth. Acta Endocrinol. (Copenh) 1993, 129, 501-504. [CrossRef]

136. Spankovich, C.; Le Prell, C.G. Healthy diets, healthy hearing: National Health and Nutrition Examination Survey, 1999-2002. Int. J. Audiol. 2013, 52, 369-376. [CrossRef]

137. Bielefeld, E.C.; Tanaka, C.; Chen, G.D.; Henderson, D. Age-related hearing loss: Is it a preventable condition? Hear. Res. 2010, 264, 98-107. [CrossRef]

138. Seidman, M.; Babu, S.; Tang, W.; Naem, E.; Quirk, W.S. Effects of resveratrol on acoustic trauma. Otolaryngol. Head Neck Surg. 2003, 129, 463-470. [CrossRef]

139. Hanci, D.; Ulusoy, S.; Acar, M.; Burukoglu, D.; Kutlu, H.M.; Bayar, M.N.; Cingi, C. Potential protective effect of resveratrol on acoustic trauma: Electron microscopy study. Eur. Rev. Med. Pharmacol. Sci. 2016, 20, 3469-3475.

140. Simşek, G.; Tokgoz, S.A.; Vuralkan, E.; Caliskan, M.; Besalti, O.; Akin, I. Protective effects of resveratrol on cisplatin-dependent inner-ear damage in rats. Eur. Arch Otorhinolaryngol. 2013, 270, 1789-1793. [CrossRef] [PubMed]

141. Duan, M.; Chen, Z.; Qiu, J.; Ulfendahl, M.; Laurell, G.; Borg, E.; Ruan, R. Low-dose, long-term caroverine administration attenuates impulse noise-induced hearing loss in the rat. Acta Otolaryngol. 2006, 126, 1140-1147. [CrossRef] [PubMed] 
142. Coleman, J.K.; Kopke, R.D.; Liu, J.; Ge, X.; Harper, E.A.; Jones, G.E.; Cater, T.L.; Jackson, R.L. Pharmacological rescue of noise induced hearing loss using N-acetylcysteine and acetyl-L-carnitine. Hear. Res. 2007, 226, 104-113. [CrossRef] [PubMed]

143. García-Alcántara, F.; Murillo-Cuesta, S.; Pulido, S.; Bermúdez-Muñoz, J.M.; Martínez-Vega, R.; Milo, M.; Varela-Nieto, I.; Rivera, T. The expression of oxidative stress response genes is modulated by a combination of resveratrol and N-acetylcysteine to ameliorate ototoxicity in the rat cochlea. Hear. Res. 2017, 358, 10-21. [CrossRef] [PubMed]

144. De Rivera, C.; Shukitt-Hale, B.; Joseph, J.A.; Mendelson, J.R.W. The effects of antioxidants in the senescent auditory cortex. Neurobiol. Aging. 2006, 27, 1035-1044. [CrossRef] [PubMed]

2018 by the authors. Licensee MDPI, Basel, Switzerland. This article is an open access article distributed under the terms and conditions of the Creative Commons Attribution (CC BY) license (http://creativecommons.org/licenses/by/4.0/). 